\title{
1 Primordial capsid and spooled ssDNA genome structures penetrate 2 ancestral events of eukaryotic viruses
}

4 Anna Munke ${ }^{1 * \#}$, Kei Kimura ${ }^{2}$, Yuji Tomaru ${ }^{3}$, Han Wang $^{1}$, Kazuhiro Yoshida ${ }^{4}$, Seiya Mito ${ }^{5}$, Yuki 5 Hongo $^{6}$, and Kenta Okamoto ${ }^{1 *}$

6 1. The Laboratory of Molecular Biophysics, Department of Cell and Molecular Biology, Uppsala 7 University, Uppsala, Sweden

8 2. Department of Biological Resource Science, Faculty of Agriculture, Saga University, Saga, Japan

9 3. Fisheries Technology Institute, Japan Fisheries Research and Education Agency, Hatsukaichi,

10 Hiroshima, Japan

11 4. Graduate School of Agriculture, Saga University, Saga, Japan

12 5. Department of Biological Resource Science, Faculty of Agriculture, Saga University, Saga, Japan

13 6. Bioinformatics and Biosciences Division, Fisheries Resources Institute, Japan Fisheries Research

*Corresponding authors

Corresponding author 1: anna.munke@desy.de

Corresponding author 2: kenta.okamoto@icm.uu.se

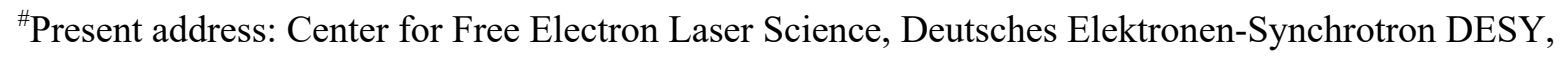




\section{Abstract}

25 Marine algae viruses are important for controlling microorganism communities in the marine 26 ecosystem, and played a fundamental role during the early events of viral evolution. Here, we have 27 focused on one major group of marine algae viruses, the ssDNA viruses from the Bacilladnaviridae 28 family. We present the capsid structure of the bacilladnavirus, Chaetoceros tenuissimus DNA virus 29 type II (CtenDNAV-II), determined at $2.3 \AA$ resolution. Structural comparison to other viruses 30 supports the previous theory where bacilladnaviruses were proposed to have acquired their capsid 31 protein via horizontal gene transfer from a ssRNA virus. The capsid protein contains the widespread virus jelly-roll fold, but has additional unique features; a third $\beta$-sheet and a long C-terminal tail, which are located on the capsid surface and could be important for virus transmission. Further, lowresolution reconstructions of the CtenDNAV-II genome reveal a partially spooled structure, an arrangement previously only described for dsRNA and dsDNA viruses.

Key words: algae virus, asymmetric reconstruction, CRESS-DNA, Cressdnaviricota, cryo-EM,

38 Bacilladnaviridae, bacilladnavirus, diatom virus, evolution, genome structure, spooled genome 
Marine algae viruses prevail massively in the oceans and greatly affect the global ecosystem by causing mortality and lysis of microbial communities, releasing organic carbon and other nutrients back into the environment (the 'viral shunt'), thereby affecting the global oxygen level, and the marine nutrient and energy cycling (Fuhrman, 1999; Suttle, 2007; Wilhelm and Suttle, 1999). Algae blooms are global phenomena of dynamic appearance and disappearance of certain algae species. The recurring patterns of algae blooms are associated with the presence of marine diatom/algae viruses (Bratbak et al., 1993; Johannessen et al., 2017; Tarutani et al., 2000). The viruses typically have a very narrow host range, thus causing host-specific mortality and control of algae host populations (Brussaard, 2004), and are therefore attractive for being used as a microbial agent against harmful algae blooms (Nagasaki et al., 1999).

Another incentive for studying marine algal viruses is for penetrating early evolutionary scenarios of primordial eukaryotic viruses. Since unicellular marine organisms were the earliest eukaryotes on earth, they were presumably host of the most ancient viruses (Dolja and Koonin, 2018; Koonin et al., 2015). The extant unicellular organisms, such as unicellular algae, therefore likely retain genetic and Structural comparison between so-called primordial viruses, such as diatom viruses, and the phylogenetically closely related viruses in the same evolutionary lineages can reveal acquired functional structures in viruses that infect higher eukaryotes such as human, animal and crop pathogens (Munke et al., 2020; Okamoto et al., 2020, 2016).

The Bacilladnaviridae viruses in this study are greatly involved in the discussions of both the global ecosystem model and early virus evolution. The Bacilladnaviridae viruses infect a diverse range of marine bloom-forming algae species (Kimura and Tomaru, 2015; Tomaru et al., 2013, 2011). These Bacilladnaviridae viruses are only infectious to their specific algae host. They lyse the host algae cells and reduce the number significantly during their propagation (Kimura and Tomaru, 2015; Tomaru et al., 2011, 2013). Understanding their host-specific transmission mechanism is the key to clarify how these ssDNA viruses affect the dynamics of bloom-forming algae species. Bacilladnaviruses carry a circular ssDNA genome of $\sim 6 \mathrm{~kb}$, which is partially double-stranded ( $\sim 700$ $800 \mathrm{bp}$ ) and encodes three proteins; one coat protein, one replication protein (Rep), and a third protein with unknown function (Kimura and Tomaru, 2015). Until recently, bacilladnaviruses have been included in the informal group CRESS DNA viruses (for circular Rep-encoding ssDNA viruses), but this group has now formed the phylum Cressdnaviricota (Krupovic et al., 2020).

Viruses with different nucleic acid types have traditionally been organised into different classes, however an increasing number of evidence has emerged during the last decade suggesting that RNADNA recombination is much more prevalent than previously recognized (Diemer and Stedman, 2012; Kazlauskas et al., 2017; Krupovic, 2013; Tisza et al., 2020). In terms of bacilladnaviruses, Kazlauskas et al suggested based on sequence homology that their capsid proteins likely have been acquired through horizontal gene transfer (HGT) from an ancestral noda-like virus (Kazlauskas et al., 2017). This is not an unreasonable scenario considering the prevalence of noda-like viruses in the aquatic environment (Wolf et al., 2020). The icosahedral capsid of the Bacilladnaviridae viruses has adapted to pack a ssDNA genome instead of a ssRNA genome, however the lack of available capsid and genome structures of icosahedral ssDNA viruses have prevented addressing this theory.

Here, we present 3D reconstructions that reveal both the capsid and genome organization of the bacilladnavirus Chaetoceros tenuissimus DNA virus type II (CtenDNAV-II). An atomic model of the capsid protein could be constructed from the $2.3 \AA$ resolution capsid structure. The capsid protein contains a jelly-roll fold with two additional extensions; a third seven-stranded $\beta$-sheet that is intertwined within the jelly-roll and C-terminal tails in two of the three proteins that form the 
86 icosahedral asymmetric unit. Both extensions, which are unique to the bacilladnaviruses, are located 87 on the capsid surface and display a higher intraspecies sequence variability compared to other parts of 88 the capsid protein, suggesting a functional role during virus transmission. The virus transmission is 89 further discussed with support from a hemagglutination inhibition assay, adsorption test and sequence 90 data. The DALI program (Holm, 2020a) was used to demonstrate that the capsid of the 91 bacilladnaviruses indeed are structurally more similar to capsids of RNA viruses than to those of other 92 ssDNA viruses, corroborating the HGT theory in early virus evolution. In addition, the first genome 93 structure of a ssDNA virus presented here suggests a spooled genome packaging mechanism, which 94 has previously only been described for dsRNA and dsDNA viruses. 


\section{Results}

\section{Summary of structure determination}

97 The structure of the CtenDNAV-II viron was determined using cryo-electron microscopy (cryo-EM). A Titan Krios microscope (Thermo Fisher Scientific) equipped with a K2 Summit direct electron detector (Gatan) (see Materials and Methods) was used to record micrographs (Supplementary Fig. 1A) and confirmed mature virons containing a DNA genome. The particles had a diameter of approximately $35 \mathrm{~nm}$ and appeared to be morphologically reproducible. The three-dimensional (3D) reconstruction of CtenDNAV-II was performed with RELION (Scheres, 2012). The capsid was reconstructed by imposing icosahedral symmetry (I4) and using 33,507 particles, whereas the genome structure was reconstructed without imposing any symmetry (C1) and using 21,559 particles. The overall resolution of the final maps were estimated using the "gold standard" Fourier shell correlation (FSC) 0.143 criterion (Henderson et al., 2012; Scheres and Chen, 2012) to $2.3 \AA$ for the capsid (Supplementary Fig. 1C) and 13 and $23 \AA$ for the two genome reconstructions (Supplementary Fig. 2). The local resolution of the capsid reconstruction was distributed between 2.3 and $9.1 \AA$ and estimated using ResMap (Kucukelbir et al., 2014) (Supplementary Fig. 1D). An atomic model was built, refined, and validated according to our cryo-EM map. Data acquisition and processing, refinement, and validation statistics are summarized in Table 1.

Table 1. Data collection, processing and refinement statistics

\begin{tabular}{|c|c|c|c|}
\hline Data collection and processing & $\begin{array}{c}\text { Capsid } \\
\text { EMD-12554 }\end{array}$ & $\begin{array}{c}\text { Genome - outer layer } \\
\text { EMD-12555 }\end{array}$ & $\begin{array}{c}\text { Genome - core } \\
\text { EMD-12556 }\end{array}$ \\
\hline Magnification & \multicolumn{3}{|c|}{140,000} \\
\hline Voltage (kV) & \multicolumn{3}{|c|}{300} \\
\hline Defocus range $(\mu \mathrm{m})$ & \multicolumn{3}{|c|}{-1.00 to -3.00} \\
\hline Microscope & \multicolumn{3}{|c|}{ Titan Krios } \\
\hline Camera & \multicolumn{3}{|c|}{$\mathrm{K} 2$} \\
\hline Total electron dose $\left(\mathrm{e}^{-} / \AA^{2}\right)$ & \multicolumn{3}{|c|}{37} \\
\hline Pixel size $(\AA)$ & \multicolumn{3}{|c|}{1.06} \\
\hline Final particle number & 33,507 & \multicolumn{2}{|c|}{21,559} \\
\hline Symmetry imposed & I4 & \multicolumn{2}{|c|}{$\mathrm{C} 1$} \\
\hline Map resolution $(\AA)(\mathrm{FSC}=0.143)$ & 2.3 & 13 & \multirow[t]{27}{*}{23} \\
\hline Map resolution range $(\AA)$ & $2.3-9.1$ & & \\
\hline Map sharpening B-factor $\left(\AA^{2}\right)$ & -70.5027 & & \\
\hline \multicolumn{2}{|l|}{ Model building and refinement } & & \\
\hline PDB & XXXX & & \\
\hline \multicolumn{2}{|l|}{ Model composition } & & \\
\hline Chains & 3 & & \\
\hline Atoms & 13933 & & \\
\hline Protein residues & 906 & & \\
\hline B-factors $\left(\AA^{2}\right)(\min /$ max $/$ mean $)$ & $4.67 / 33.32 / 12.03$ & & \\
\hline \multicolumn{2}{|l|}{ Bonds (RMSD) } & & \\
\hline Length $(\AA)$ & 0.005 & & \\
\hline Angle $\left(^{\circ}\right)$ & 0.724 & & \\
\hline Validation & 1.79 & & \\
\hline MolProbity score & 1.79 & & \\
\hline Clash score & 5.60 & & \\
\hline \multicolumn{2}{|l|}{ Ramachandran plot (\%) } & & \\
\hline Outliers & 0.00 & & \\
\hline Allowed & 4.01 & & \\
\hline Favoured & 95.99 & & \\
\hline Rotamer outliers (\%) & 1.90 & & \\
\hline $\mathrm{C} \beta$ outliers $(\%)$ & 0.00 & & \\
\hline CaBLAM outliers (\%) & 1.46 & & \\
\hline $\mathrm{CC}$ (overall) & 0.84 & & \\
\hline EMRinger score & 6.16 & & \\
\hline d99 masked (full/half1/half2) & $2.2 / 3.3 / 3.3$ & & \\
\hline d99 unmasked (full/half1/half2) & $2.1 / 3.1 / 3.1$ & & \\
\hline
\end{tabular}




\section{The capsid protein displays different conformations within the asymmetric unit}

115 The CtenDNAV-II capsid displays $\mathrm{T}=3$ symmetry, i.e. 180 capsid protein protomers assemble such

116 that the asymmetric unit comprises 3 capsid subunits in 3 quasi-equivalent positions termed $\mathrm{A}$, B, and

117 C (Fig. 1A). For subunit A residues 64-72 and 77-371 were modelled, for subunit B residues 64-371

118 were modelled, and for subunit $\mathrm{C}$ residues 64-357 were modelled. The C-terminus of the A and B

119 subunits form long tails that end on the capsid surface around the 3- and 5-fold axes respectively.

120 Here, the last 19 residues could not be modelled (Fig. 2C). Additional density was however visible in

121 the map when the contour level was decreased (Supplementary Fig. 2), indicating that the C-terminus

122 forms flexible protrusions on the capsid surface. Another 14 residues were unmodelled in the C-

123 terminus of the $\mathrm{C}$ subunit (red rectangle in Fig. 2C), nevertheless it is clear that, in contrast to the A-

124 and B-subunits, the C-terminus is directed towards the capsid interior (Fig. 1C). Unmodelled density is

125 observed on the inside of the capsid below the $\mathrm{C}$ subunits (Supplementary Fig. 3), which presumably

126 originates from the C-terminus of the $\mathrm{C}$ subunit, since corresponding unmodelled density was not

127 visible below the $\mathrm{A}$ and $\mathrm{B}$ subunits (Supplementary Fig. 3A). Different conformations and/or

128 flexibility were also observed between the three subunits in the N-termini (Fig. 1C), which are all

129 located on the inside of the capsid. The first 63 residues of the N-terminus could not be modelled in

130 any of the three subunits (Fig. 2C). The modelled termini and corresponding cryo-EM map are

131 displayed in Fig. 1D. Apart from the termini, the three subunits have very similar structures (Fig. 1C).

132 In addition, unmodelled density, presumably originating from an ion or small molecule, was visible in

133 the interface of the three subunits that constitute one protomer (Supplementary Fig. 4). The density is

134 surrounded by six arginine residues (R86 and R272), which is an unusual finding among viruses.

135 Similar arginine rings have however been described for the HIV virus, in which the arginines interact

136 with polyanions such as nucleoside triphosphates (dNTPs) and myo-inositol hexaphosphate (IP6)

137 (Mallery et al., 2018). 

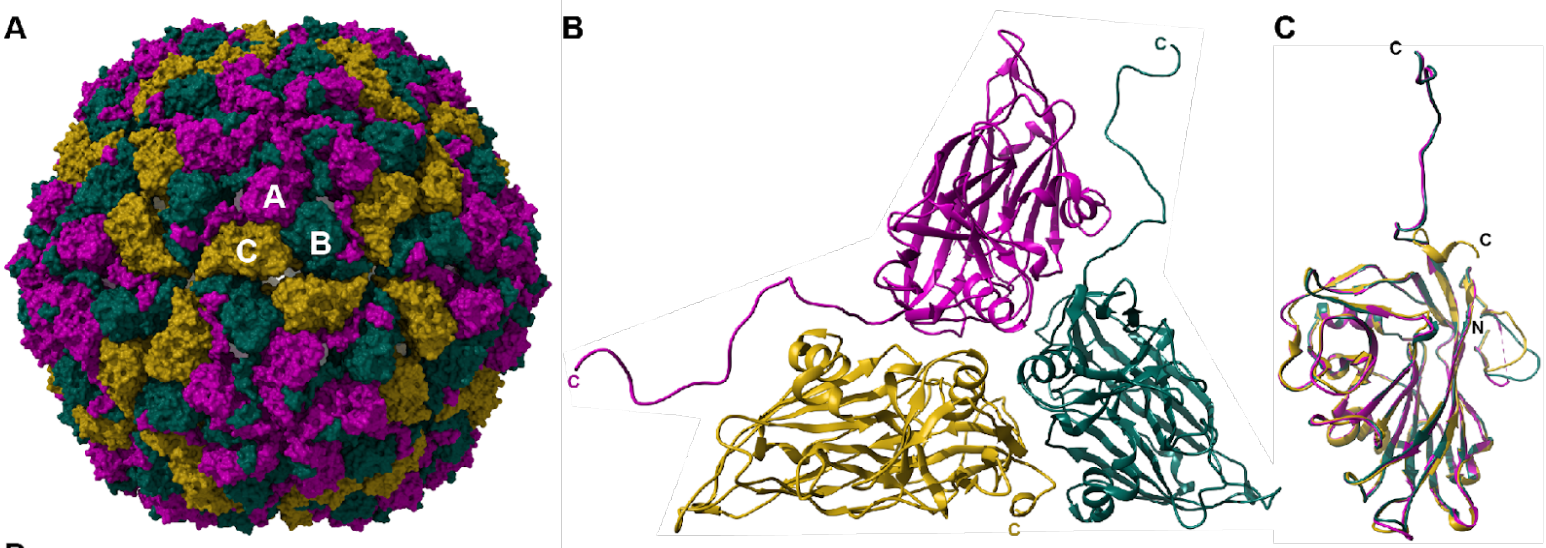

D
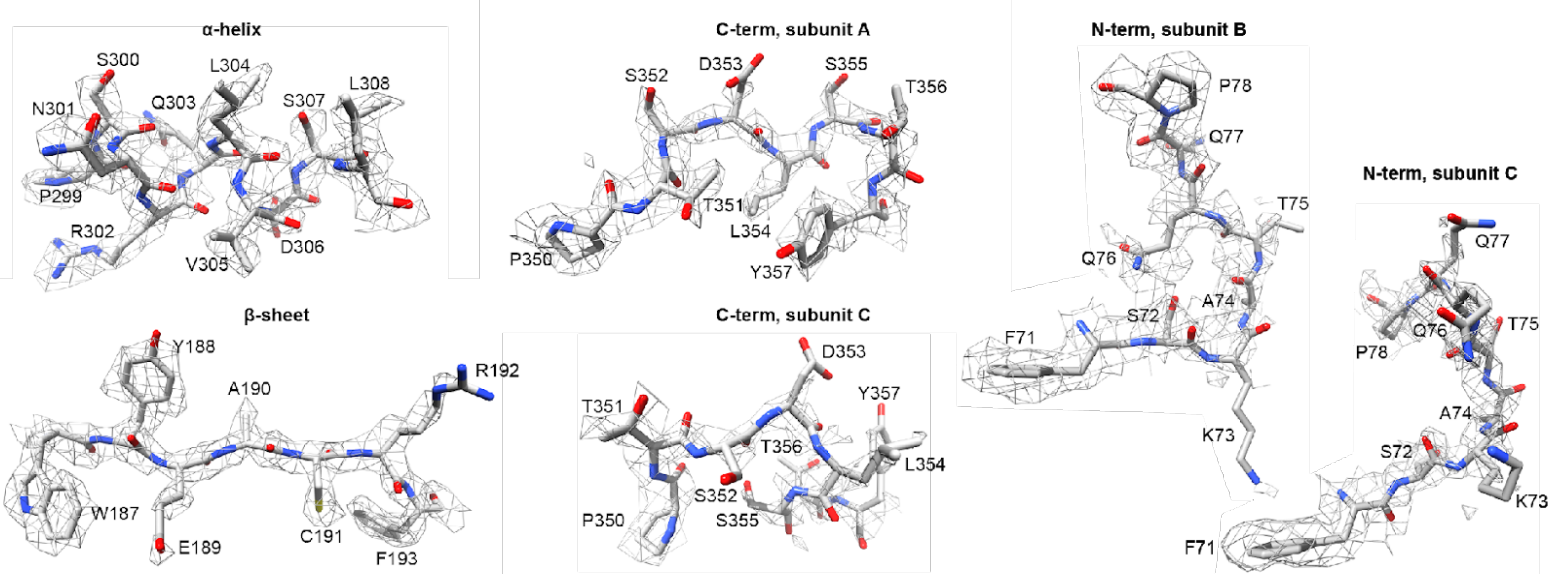

Figure 1. Atomic model of the CtenDNAV-II capsid. The three subunits, A, B and C, are coloured purple, green and yellow, respectively, in panel A-C. (A) The entire capsid rendered with a surface representation viewed down an icosahedral two-fold axis. (B) The secondary structure of one single asymmetric unit viewed from the outside. (C) Superimposition of the three subunits. (D) Refined side chains of representatives of secondary structural elements and areas that differ between the three subunits.

\section{The capsid protein jelly-roll fold has unique features}

The canonical viral jelly-roll consists of eight anti-parallel $\beta$-strands that are named from B to I and arranged in two four-stranded sheets (BIDG and CHEF). The loops connecting each strand are named BC, CD, etc. (Harrison et al., 1978; Rossmann et al., 1985). For CtenDNAV-II, the two sheets are formed by strands BIDD'G and C'"C'CHEF, respectively (Fig. 2A-C), thus containing three additional strands (D', C' and C', ) compared to the standard viral jelly-roll fold. In addition, a third antiparallel $\beta$-sheet with seven strands is intertwined within the jelly-roll, i.e. strands from the third sheet are formed by extensions of loops $\mathrm{CD}, \mathrm{EF}$ and $\mathrm{GH}$ of the jelly-roll. The third sheet, which is located on the capsid surface, is thus composed of two C-strands (C',' and C',' '), two E-strands (E' and E'), and three G-strands (G', G" and G"') (Fig. 2B). In conclusion, the jelly-roll fold of CtenDNAV-II has three unique features: three additional strands, an extra surface-exposed $\beta$-sheet, and C-terminal tails in subunit $\mathrm{A}$ and $\mathrm{B}$. 
A

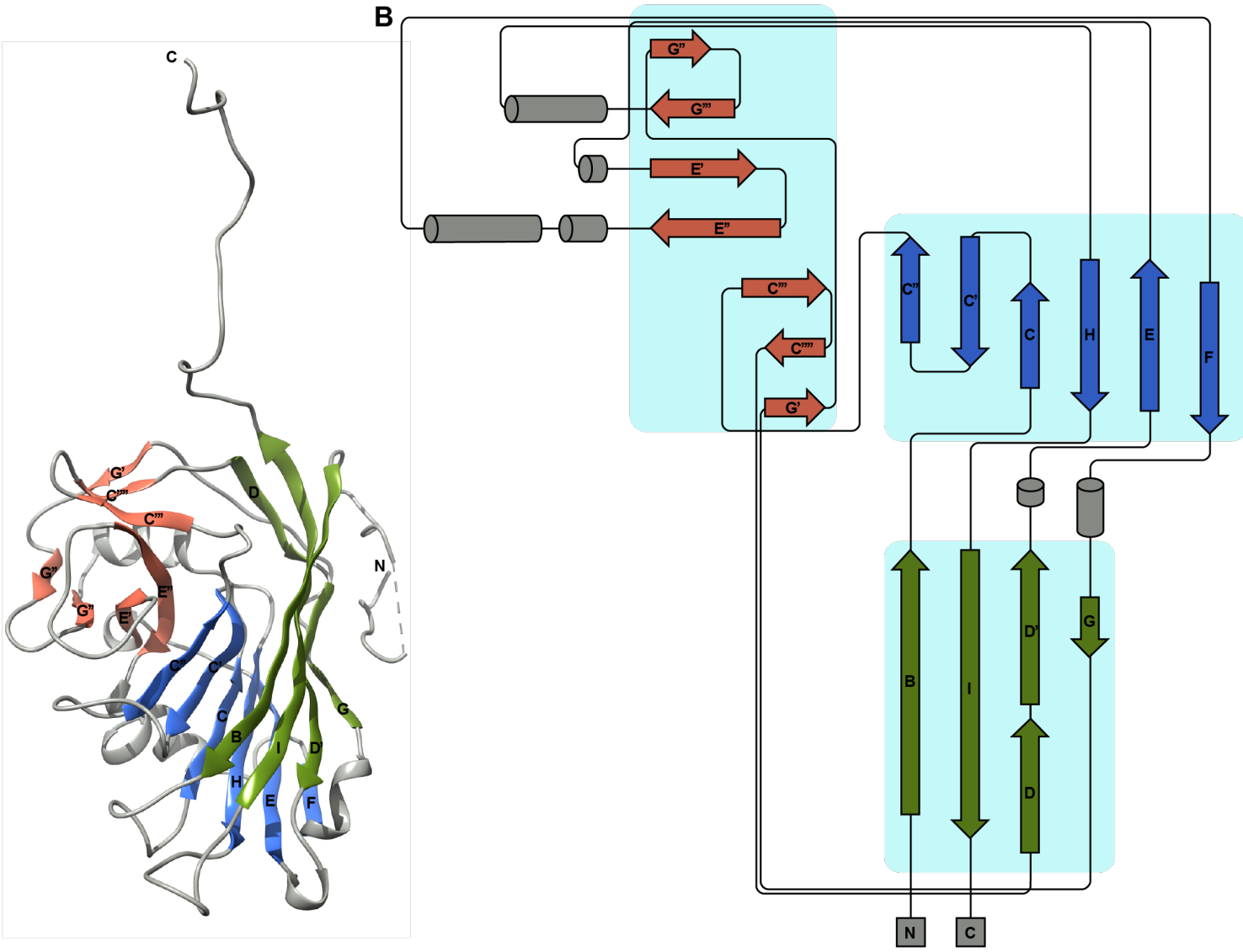

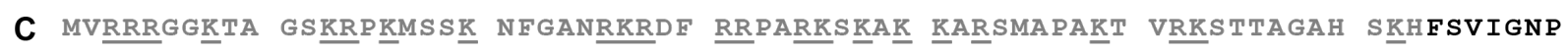
FSKATQQPQI PDGRMLSLP RRCQLVTEIR NNVTVGSNPT YILVIAPSLGL AFQAYQDTNV PGGLDSSVYY LQNRGCTVRA NISATSIENY NDIAKWRIVS QGINLKLNNV FDENDGWYEA CREQHDWTPD ELCLRSTEND ASTISQDEDL E" VMGVISSSFM NGALNTIGNN MVEQRGYESG LIKNIHKRMF QLHNNTSAIR PKTLQGQFNY GSEITFSGTE SEARFTDVPS NRQLVDSLWH NDYDCILIKL YPRENTGAAG QTGSALIVNA IQNLELQYSP

Figure 2. Capsid protein topology and structural organisation. The $\beta$-strands are coloured according which $\beta$-sheet they belong to. The $\beta$-strands within the green and blue $\beta$-sheets are named alphabetically according to the conventional jelly-roll fold nomenclature (B to I) (A) The secondary structure of subunit A. (B) Schematic diagram of the secondary structure. (C) The amino acid sequence of the CtenDNAV-II capsid protein, starting from residue 1. Each line has 70 residues and is further subdivided into blocks of 10 residues by spaces within the sequence. The residue numbering is the same as in PDB entry 7NS0. Modelled and unmodelled residues are coloured black and grey, respectively. Residues highlighted with red rectangles were unmodelled in one of the subunits: F73P76 in subunit A and H358-L371 in subunit C. The assigned secondary structure is shown schematically above the sequence. The underlined residues in the unmodelled $\mathrm{N}$-terminus indicate positively charged residues.

\section{Capsid proteins from CtenDNAV-II and ssRNA viruses are similar} 2020) include viruses from families Ciroviridae (eg. 3R0R and 5ZJU) and Geminiviridae (eg.6F2S and 6EK5). The capsid proteins in viruses from these two families also contain a jelly-roll domain, but lack the third surface-exposed $\beta$-sheet and N-terminal tail found in CtenDNAV-II. A search with the 
DALI program (Holm, 2020a) revealed that the CtenDNAV-II capsid protein is more similar to capsid proteins of ssRNA viruses than to ssDNA viruses (Fig. 3A), corroborating the previous HGT theory by Kazlauskas et al (Kazlauskas et al., 2017). The closest ssDNA virus is that of Beak and feather disease virus (Circoviridae), which ends up on 11th place (z-score 8.4) behind ten RNA viruses. Highest similarity is found between ssRNA viruses from families Carmotetraviridae, Alphatetraviridae and Nodaviridae that resulted in z-scores of 14.4-15.1 (Fig. 3A). For interpretation of the results from DALI see Holm (2020) (Holm, 2020b). Superimpositions between capsid proteins from CtenDNAV-II and representatives from each family show that those RNA viruses with highest zscore all have surface projections in addition to the jelly-roll, albeit with different folds, that occupy similar positions as the third $\beta$-sheet of CtenDNAV-II (Fig. 3B). However, in none of the other viruses the projection is as intertwined with the jelly-roll as for CtenDNAV-II, and instead the protrusion often forms a separate domain with a linker region, such as the Immunoglobulin (Ig)-like domain of Providence virus (Carmotetraviridae) (left most panel in Figure 3B) (Speir et al., 2010). The Cterminal surface protruding tail in subunit $\mathrm{A}$ and $\mathrm{B}$ of CtenDNAV-II is a unique feature that is not observed in any of the other virus families (Fig. 3B).

In addition to the $\mathrm{C}$-terminal tail and $\beta$-sheet surface projection, superimpositions performed by the DALI server also revealed non-conserved loops (HI and C'C'') from the jelly-roll (Supplementary Fig. 5A, B). These areas are all located on the capsid surface clustered together around the five- and three-fold axes (Supplementary Fig. 5C).

A

\begin{tabular}{|c|c|c|c|c|c|c|}
\hline PDB & Name & Family & Genome & z-score & rmsd & Residues \\
\hline 2qqp & Providence virus* ${ }^{\star}$ & Carmotetraviridae & ssRNA & 15.1 & 2.9 & 209 \\
\hline $3 s 6 p$ & Helicoverpa Armigera Stunt virus* & Alphatetraviridae & ssRNA & 14.9 & 2.9 & 208 \\
\hline $4 \mathrm{ftb}$ & Flock House virus ${ }^{*}$ & Nodaviridae & SSRNA & 14.9 & 3.1 & $\overline{201}$ \\
\hline $2 \mathrm{bbv}$ & Black Beetle virus & Nodaviridae & ssRNA & 14.7 & 2.9 & 199 \\
\hline 1ohf & Nudaurelia capensis omega virus & Alphatetraviridae & ssRNA & 14.5 & 3.0 & 207 \\
\hline $1 \mathrm{f} 8 \mathrm{v}$ & Pariacoto virus & Nodaviridae & ssRNA & 14.5 & 3.2 & 204 \\
\hline 1 nov & Nodamura virus & Nodaviridae & ssRNA & 14.4 & 3.1 & 202 \\
\hline 3ide & Infectious pancreatic necrosis virus ${ }^{*}$ & Birnaviridae & dsRNA & 12.1 & 3.0 & 192 \\
\hline $2 \mathrm{df7}$ & Infectous brusal disease virus & Birnaviridae & dsRNA & 12.1 & 3.3 & 198 \\
\hline $2 i z w$ & Ryegrass mottle virus* & Solemoviridae & ssRNA & 8.8 & 3.3 & 162 \\
\hline $5 z j u$ & Beak and feather disease virus* & Circoviridae & ssDNA & 8.4 & 4.1 & 155 \\
\hline
\end{tabular}
B

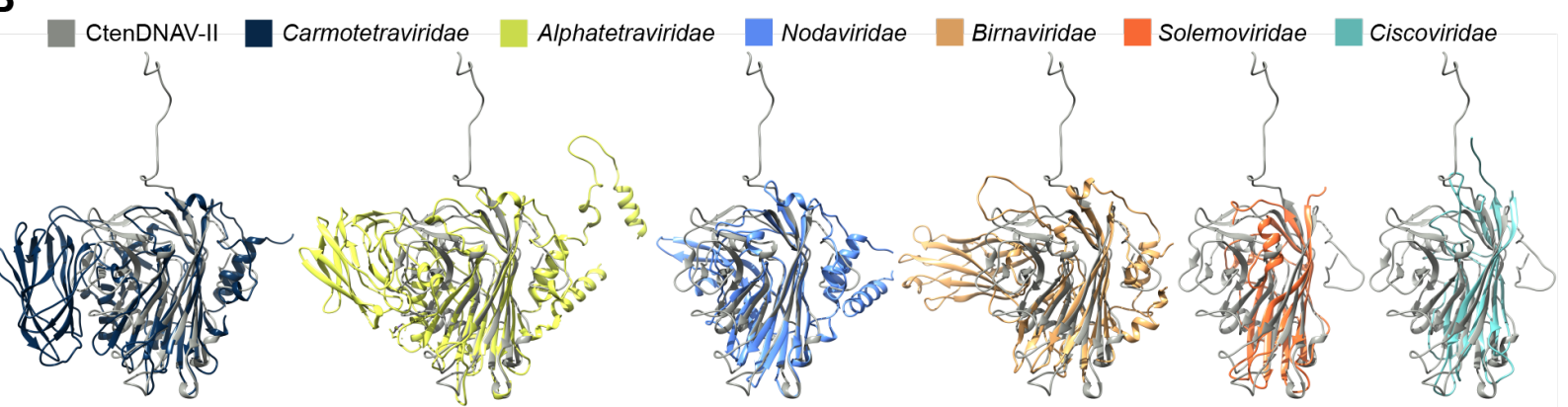

Figure 3. Structural comparison of the CtenDNAV-II capsid protein with corresponding proteins from other viruses. (A) DALI-based structural comparison where the top 11 unique viruses (i.e., not unique PDB entries) with highest z-score are listed. Viruses indicated with ${ }^{*}$ were used for the superimpositions in (B). For each comparison the z-score, rmsd and the number of residues that were used for the alignment are listed. (B) Superimpositions of the CtenDNAV-II capsid protein (gray) with representatives from each family listed in (A). 
Intraspecies sequence variability in surface-exposed regions

Since the presented structure is the first of a virus from the Bacilladnaviridae family and its most structurally close-related viruses are ssRNA viruses (Fig. 3), we sequenced (see Supplementary methods) 15 CtenDNAV-II strains with the anticipation of improving our understanding of the structure. The alignment (Supplementary Fig. 6) revealed 11 areas with mutations, of which 9 are surface-exposed primarily on the C-terminal tail (R365, V367, A380 and R390) or beta-sheet projection (A211-T213, T285 and S291) (Fig. 4). Thus, the mutated areas correlate with the unique structural features for the CtenDNAV-II capsid protein that was identified from the superimpositions with the structurally closely related viruses (Fig. 3B and Supplementary Fig. 5A). Interestingly, two strains, 2-6_11V10 and 2-6_11V04, shared the same C-terminus sequence, which were completely different from the other 13 strains (Fig. 4 and Supplementary Fig. 6).

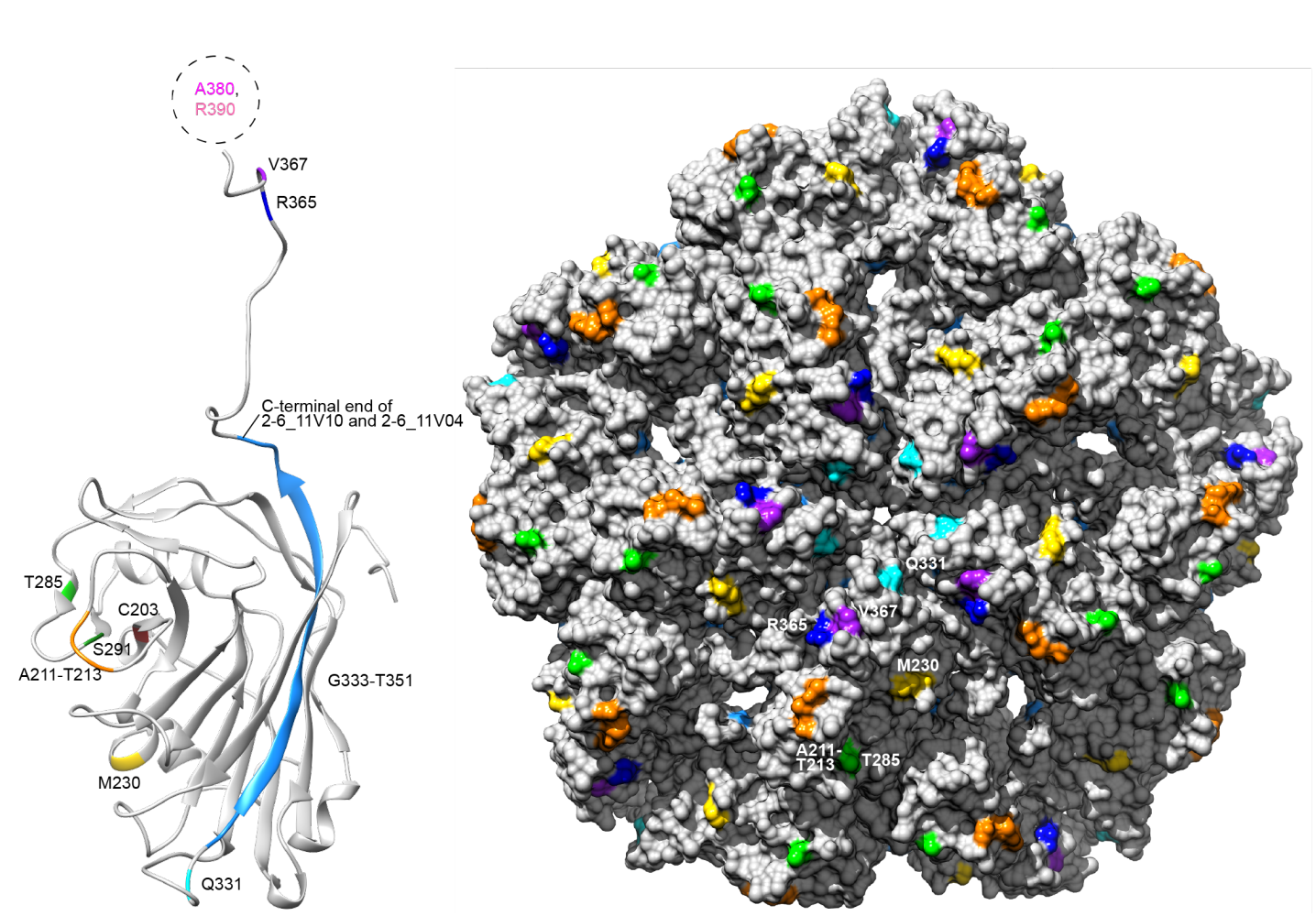

Figure 4. Location of mutations identified among CtenDNAV-II strains. Subunit A (left), and a pentamer viewed from the outside looking down the five-fold axis (right) with mutations having the same colour code as in Supplementary Figure 6. Two mutations (A380 and R390), in dashed circle, are located in the unmodelled region of the $\mathrm{C}$-terminus.

\section{Chaetoceros tenuissimus viruses employ different transmission strategies}

Sialic acids, acidic sugars that terminate glycan chains on the cell surface, are one of the common viral receptors, and well-described for vertebrate viruses such as influenza, corona and polyoma. The existence of sialic acids in algae and the discussions on their importance for algae virus interactions is however more recent (Fulton et al., 2014; Munke et al., 2020; Wagstaff et al., 2018). Wagstaff and coworkers could demonstrate that Prymnesium parvum is capable of de novo synthesis of the deaminated sialic acid Kdn, and through bioinformatics analysis, that sialic acid biosynthesis is widespread among microalgae. However, we failed to detect homologous sequences in C. tenuissimus (Accession numbers BLLK01000001-BLLK01000085) for any of the synthesases identified in Wagstaff et al. To further corroborate our findings, we performed a classical hemagglutination inhibition (HI) assay (see Supplementary methods) to investigate the sialic acid-binding capability of CtenDNAV-II. An RNA virus (CtenRNAV-II) (family Marnaviridae) that infects the same diatom host was also tested as a 
representative of another major group of diatom viruses. The HI test demonstrated that CtenRNAV-II shows partial HI activity, especially at high concentrations (no and 2 times dilution), while CtenDNAV-II did not show any HI activity (Supplementary Fig. 6). In conclusion, both the synthesase sequence analysis and HI assay indicate that the transmission of CtenDNAV-II is not sialic acidmediated.

\section{Chaetoceros tenuissimus viruses display different host cell affinities}

The adsorption kinetics of CtenDNAV-II and CtenRNAV-II were examined with two diatom species including three culture strains (see Supplementary methods). The adsorption of CtenDNAV-II was not detected for Chaetoceros socialis f. radians NIES-3713 (Supplementary Fig. 8). This result is reasonable, since the DNA virus does not lyse C. socialis (Kimura and Tomaru 2015). Although CtenDNAV-II lyses both C. tenuissimus strains NIES-3714 and NIES -3715 (Kimura and Tomaru 2015), significant adsorption of the virus was only observed with the former strain (Supplementary Fig. 8). As for CtenRNAV-II, significant adsorption was detected for C. tenuissimus strain NIES3715, but not to other diatom species and strains (Supplementary Fig. 8). A previous study reported that CtenRNAV-II lyses C. tenuissimus strain NIES-3715, but not NIES-3714, and has a low lytic activity on $C$. socialis f. radians (Kimura and Tomaru 2015). Therefore, the present result would be consistent with the phenotypic relationship and suggest that the specific adsorption of CtenRNAV-II is determined at host strain level. In conclusion, the degree of the virus and diatom host cell affinities would be determined by combinations of the virus species and host strain level.

\section{CtenDNAV-II genome structure is partially spooled}

The genome organization of CtenDNAV-II is shown in Figure 5. The CtenDNAV-II genome consists of an ordered outer layer (Fig. 5B and E) that is partially spooled around a disordered core (Fig. 5C). The outer layer (EMDB-12555) was reconstructed at $13 \AA$ by masking out the capsid, while the core (EMDB-12556) was reconstructed at $23 \AA$ by using a spherical mask (see Materials and Methods for details). The reconstruction of the outer genome layer displays a coil of three turns that are positioned between the icosahedral 5-fold axes (Fig. 5E). On each side of the three turns are additional DNA fragments that do not follow the same spooling arrangement (Fig. 5B). The spooled genome packaging has previously only been described in viruses with double stranded genomes (Ilca et al., 2019; Liu et al., 2019), whereas ssRNA viruses instead have a branched network formed by the genome secondary structure (Dai et al., 2017; Gorzelnik et al., 2016; Koning et al., 2016). The distance between the parallel turns are about $28 \AA$ (Fig. 5E), which is about the same distance as what has been described for dsRNA viruses (Ilca et al., 2019). Below each icosahedral 5-fold axis of the capsid the reconstruction of the outer genome layer displays protrusions towards the capsid (Fig. 5B and E). However, these protrusions are not necessarily true at every position and could partially be artefacts from the reconstruction, which is supported by the fact that some of the protrusions loose connections to the remaining outer layer when the contour level is decreased while other protrusions remain intact. Connections between the outer genome layer and the core seem to be confined to two specific areas on opposite sides of the outer layer (Supplementary Fig. 9). Supplementary Movie 1 shows the asymmetric reconstruction in relation to the capsid. 
A

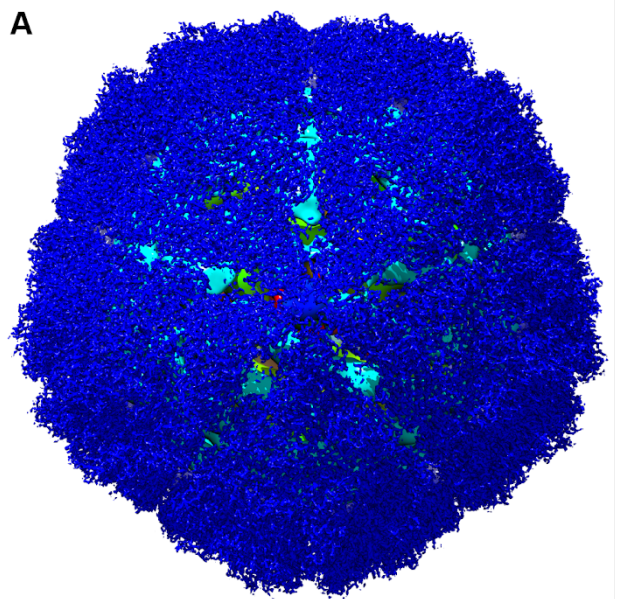

D

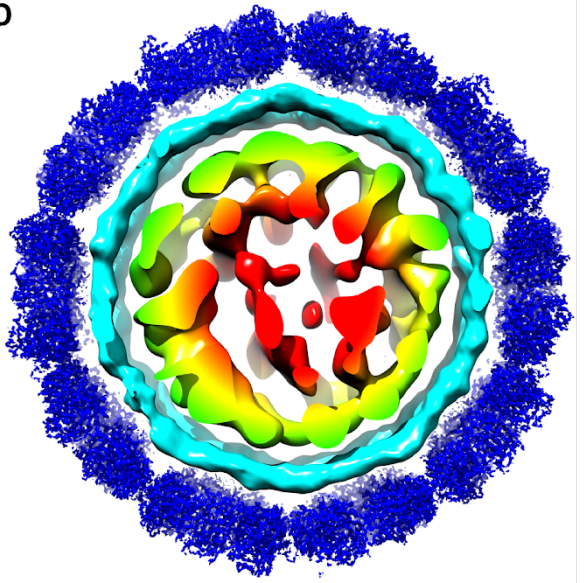

B

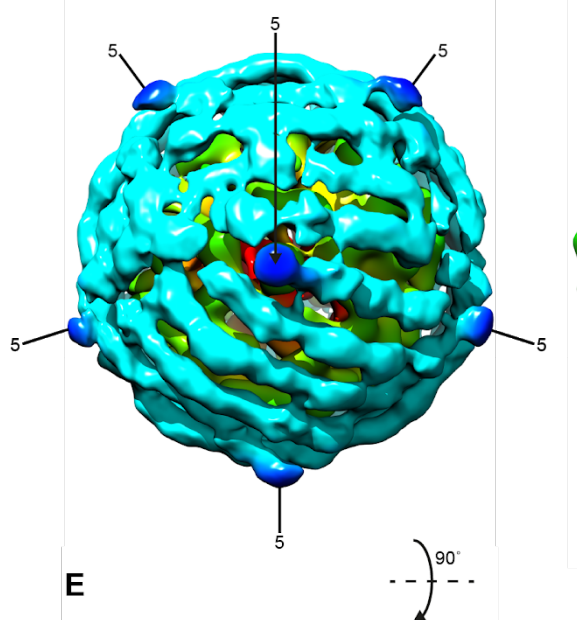

C

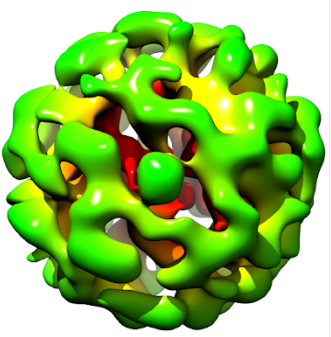

Figure 5. Asymmetric reconstructions of CtenDNAV-II radially coloured from red to blue. (A) The capsid (blue) reconstructed with icosahedral symmetry and the asymmetric reconstructions sighted below viewed down the icosahedral five-fold axis. (B) Same view as (A) but with the icosahedral reconstruction removed. A protrusion (blue) from the outer genome layer (cyan) is visualised at each five-fold axis (labelled as 5). (C) Same view as in (A) and (B) but with the icosahedral and outer layer reconstructions removed. (D) A thin slice of the reconstructions shown in (A). (E) The picture in (B) has been rotated $90^{\circ}$. The resolution $(\mathrm{FSC}=0.143$ ) of the outer layer and core are $13 \AA$ and $23 \AA$, respectively. The FSC curves are shown in Supplementary Figure 2. 


\section{Discussion}

\section{Transmission mechanisms of Chaetoceros tenuissimus viruses}

This paper describes the first structure (Figs. 1-2) of a Bacilladnaviridae virus, which is one of the major groups of marine bloom-forming algae viruses. The CtenDNAV-II capsid protein contains the widespread virus fold, the jelly-roll, but has in addition a third $\beta$-sheet and a C-terminal extension, both of which form surface domains in close proximity to each other (Supplementary Fig.5) on the capsid surface and that to our knowledge are unprecedented in other jelly-roll fold viruses determined to date (Fig. 3, Supplementary Figs. S2 and S5). We have previously determined the structure of a C. tenuissimus infecting RNA virus (family Marnaviridae), which has a primordial surface loop and lacks the receptor-binding motif found in other structurally and phylogenetically related animal viruses (Munke et al., 2020). This implies that these host-specific algae viruses have unique receptorbinding mechanisms. The molecular details on the infection mechanisms of diatom viruses are unknown. However, a putative transmission route could exist through interactions with host sialic acids, since sialic acid biosynthesis has been shown to be widespread among microalgae (Wagstaff et al., 2018). In addition, many structurally related jelly-fold viruses interact with sialic acids for cell entry, such as polyomaviruses via their conserved surface loops (Ströh et al., 2020). Likewise, the C-terminal P-domain of the betanodavirus capsid protein interacts with sialic acids, and its deletion affects virulence and host specificity (Liu et al., 2005; Moreno et al., 2019). The combined results of no homologous sequences in C. tenuissimus for any of the synthesases identified in Wagstaff et al (Wagstaff et al., 2018), with the lack of HI activity (Supplementary Fig. 6), strongly refute a sialic acid interaction between CtenDNAV-II and its host. This implies that the CtenDNAV-II virus employs an alternative receptor and transmission strategy. The RNA virus infecting the same diatom host (CtenRNAV-II) did however interact weakly with the mammalian sialic acid, which could indicate that microalgae might have sialic acids or structurally related acidic sugars that have not yet been described in the literature. The CtenRNAV-II virus is phylogenetically closely related to Picornaviridae viruses, some of which use sialic acids as their entry receptor (Zocher et al., 2014). The different receptor-binding strategies employed by the DNA and RNA virus could explain their different host cell affinities (Supplementary Fig. 8).

Nevertheless, the CtenDNAV-II capsid protein has two unique surface features, the C-terminal tail and $\beta$-sheet projection, compared to the most structurally close-related viruses (Fig. 3). These extensions from the jelly-roll fold were in addition found to have an increasing number of mutations between different virus species compared to other parts of the structure (Fig. 4 and Supplementary Fig. 6). Host specificity of algae viruses have previously been correlated with surface-exposed amino acid substitutions (Nagasaki et al., 2005). Future research on CtenDNAV-II strains and their infection patterns might reveal similar relationships. The locations of the mutations do however make the $\beta$ sheet and C-terminal extensions putative interaction candidates.

\section{Structural insights on eukaryotic jelly-roll fold viruses in evolution}

About $30 \%$ of all viruses adopt the single jelly-roll fold (Krupovic and Koonin, 2017), and the results presented herein provide structural insights on the evolution of this fold. Our findings corroborate the theory that the jelly-roll capsid proteins of ssDNA, ssRNA and dsRNA viruses originate from the same virus with a primordial jelly-roll fold (Fig. 3) (Kazlauskas et al., 2017; Krupovic and Koonin, 2017). According to the HGT theory, the capsid protein of CRESS-DNA viruses could have been acquired from the ssRNA protist viruses in early evolutionary events (Kazlauskas et al., 2019, 2017). Indeed, the capsid protein of CtenDNAV-II is structurally more similar to ssRNA and dsRNA viruses than to other CRESS-DNA viruses (Fig. 3). Because the rolling-circle replication proteins of CRESSDNA viruses are polyphyletic, the capsid protein genes have probably been acquired from ssRNA 
viruses on several independent occasions and at different time-points in evolution (Krupovic, 2013). Similarly, icosahedral dsRNA viruses are thought to have originated from ancestral ssRNA nodaviruses and tetraviruses (Coulibaly et al., 2005). Yet another example includes the large CRESSDNA virus FLiP (Flavobacterium-infecting, lipid-containing phage) that shows a dsDNA adenoviruslike capsid structure (Laanto et al., 2017), which potentially links CRESS-DNA and dsDNA viruses. To put our new structural insights into a broader context, we have updated the putative emergence of the ssDNA, ssRNA and dsRNA viruses (Fig. 6).

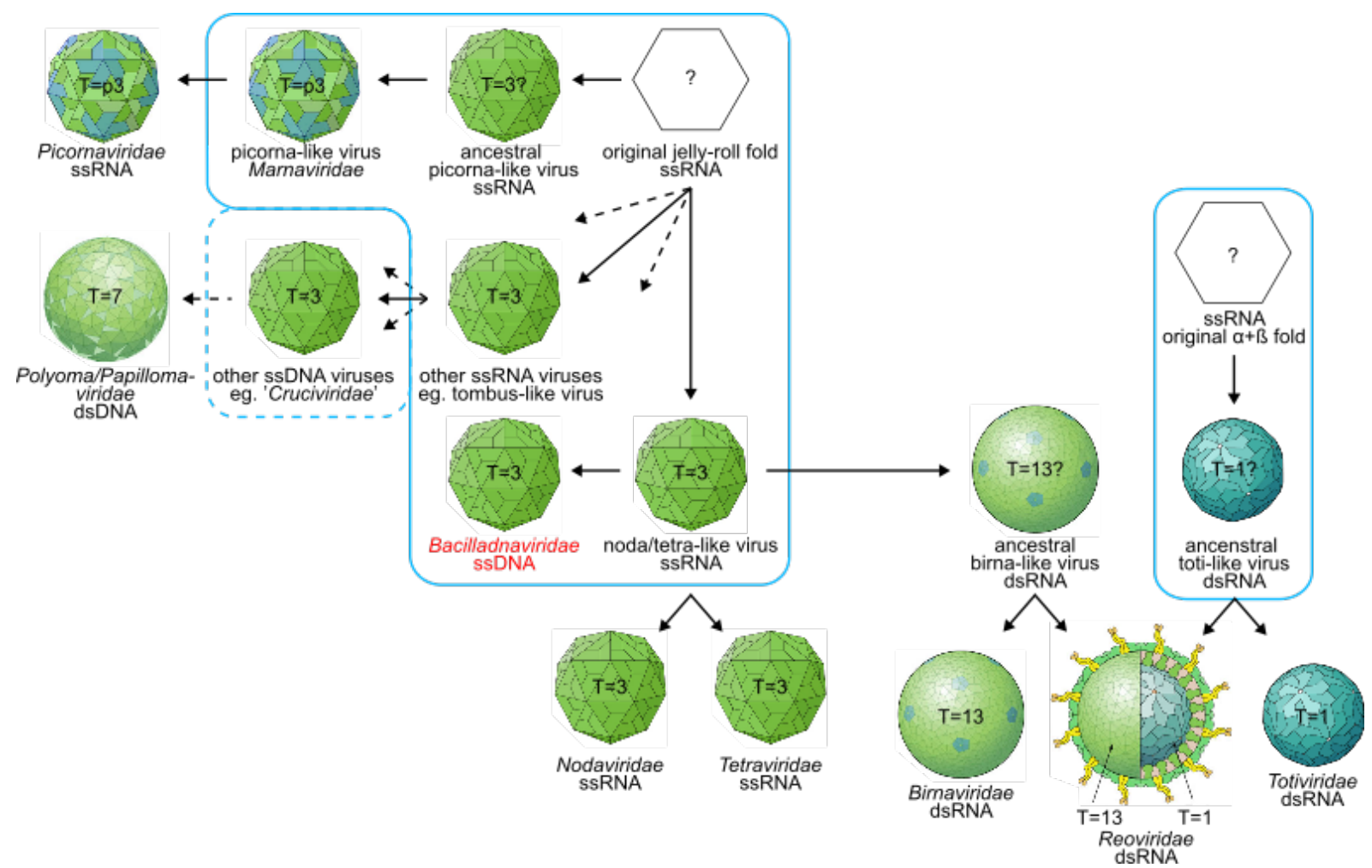

Figure 6. A scheme depicting the putative emergence of virus capsids carrying different nucleic acid genomes. The figure illustrates based on current knowledge the most relevant virus groups and the evolutionary relationship between their virus capsids. Events that likely took place at an early stage of evolution in ancient algal pools are circled in blue. The dashed blue line represents that ssRNA and ssDNA virus recombination has occurred at several independent occasions, at different time points in evolution. The figure is based on results described in this paper as well as previous results and discussions (Chiba et al., 2020; Coulibaly et al., 2005; Diemer and Stedman, 2012; Kazlauskas et al., 2019; Krupovic, 2013; Munke et al., 2020; Okamoto et al., 2020, 2016). The viron pictures were derived from ViralZone, SIB Swiss Institute of Bioinformatics (Hulo et al., 2011) (https://viralzone.expasy.org/) licensed under a Creative Commons Attribution 4.0 International Licens.

Animal and plant ssRNA, dsRNA and CRESS-DNA viruses with icosahedral capsids that contain the jelly-roll fold should have acquired additional structural motifs for infecting their hosts. The primordial jelly-roll capsid protein structure of the CtenDNAV-II highlights the acquired features of these viruses that infect multicellular eukaryotes. Examples of such acquisitions are the Ig-like domain of tetraviruses and the P-domain of nodaviruses and birnaviruses (Fig. 3). These structures have been described as putative receptor-binding domains of those viruses; however, an exhaustive characterization still remains. The external Ig-like domain in tetraviruses (family Carmotetraviridae 
and Alphatetraviridae) is believed to function in receptor binding to host cells (Helgstrand et al., 2004; Penkler et al., 2016). Some Nodaviridae viruses, so-called gammanodaviruses, have an external Pdomain that is important for virus attachment and entry (Ho et al., 2018), whereas the capsid proteins of other nodaviruses retain primordial features that are structurally much more similar to the CtenDNAV-II capsid (Johnson et al., 2001) (Fig. 3). The dsRNA Birnaviridae viruses display an external highly antigenic P-domain that is likely involved in the initial attachment to the host cells (Coulibaly et al., 2005; Garriga et al., 2006). The CRESS-DNA polyomaviruses possess a conserved jelly-roll fold VP1 protein, and has acquired extra minor proteins VP2 and VP3 that has an ER-tocytosol penetration function during cell entry (Inoue and Tsai, 2011). Several studies report on the presence of a large number of diverse unclassified animal CRESS-DNA viruses, including putative human pathogenic viruses ( $\mathrm{Ng}$ et al., 2015; Phan et al., 2015; Tisza et al., 2020). Structural comparison of their capsid proteins with that of CtenDNAV-II could reveal the acquired features of these animal CRESS-DNA viruses.

\section{2}

373

374

\section{A spooled genome requires structural adaptations of the capsid}

The technological and computational improvements in cryo-EM structure determination have led to an increasing number of virus genome structures during the last decade. However, determining the genome structure within the symmetric icosahedral capsid still remains challenging, especially for single-stranded genomes (Koning et al., 2016). By employing a previously described method of subtracting the contribution of the capsid (Ilca et al., 2019), we were here able to demonstrate the first entire genome structure of a ssDNA virus (Fig. 5 and Supplementary Movie 1).

Previous cryo-EM studies have revealed three types of genome organization for non-enveloped icosahedral viruses. The dsDNA and some dsRNA viruses such as Bacteriophage $\Phi 6$ forms spooled genome structures with certain interfilament spacing (Ilca et al., 2019; Liu et al., 2019; Wang et al., 2019). Segmented dsRNA reoviruses instead form non-spooled or partially-spooled genomes with pseudo-D3 symmetry that interact with the RNA-dependent RNA polymerase (RdRp) (Ding et al., 2019; Liu and Cheng, 2015; Wang et al., 2018; Zhang et al., 2015). The third variant is found in Leviviridae viruses where the secondary structure of their ssRNA genomes form a branched network of stem-loops (Dai et al., 2017; Gorzelnik et al., 2016; Koning et al., 2016), however it remains unknown if a similar organisation is found in other ssRNA viruses.

The structure presented here is the first entire genome structure for a ssDNA virus. The genomes of ssDNA viruses have the capability to form biologically functional secondary structures similar to ssRNA viruses (Muhire et al., 2014) and since the capsid gene of bacilladnaviruses has been horizontally transferred from ssRNA viruses, a similar branched structural network is imaginable also for ssDNA viruses. However, the structure of the CtenDNAV-II genome is much more similar to those of the spooled dsDNA or the partially spooled dsRNA genomes (Fig. 5 and Supplementary Movie 1). Two major questions arise for the genome packaging of bacilladnaviruses. The first question is how to stabilize the spooled ssDNA genome without a secondary structure organization? Potentially, a partial secondary structure might exist, and could together with the dsDNA segment that exist in bacilladnaviruses (Kimura and Tomaru, 2015; Tomaru et al., 2011, 2013), be sufficient for stabilizing the ssDNA genome inside the capsid. Another possibility is that the dsDNA gene of bacilladnaviruses help stabilizing the ssDNA without having any secondary structure. The second question is how the ssRNA virus-like capsid protein was adapted to packing the dsDNA/dsRNA-like spooled genome of the CtenDNAV-II? The spooled genome structures of the dsDNA and dsRNA viruses are packaged by flexible interactions between the capsid protein and the genome. The interactions are mediated by small contacts with hydrophobic and/or positively-charged amino acid residues of their capsid proteins (Ding et al., 2019; Ilca et al., 2019; Liu and Cheng, 2015, 2015; Wang et al., 2019, 2018; Zhang et al., 2015). In contrast, the secondary structure of the (+)ssRNA viral genome binds specifically to the 
capsid (Dai et al., 2017; Gorzelnik et al., 2016; Hesketh et al., 2018; Koning et al., 2016). Our 407 hypothesis is that the unmodelled $\mathrm{N}$-terminus, and possibly the $\mathrm{C}$-terminus of the $\mathrm{C}$-subunit, which 408 both possess numerous positively charged amino acids, interact with the ssDNA genome, in a flexible and non-specific manner similar to dsDNA and dsRNA viruses. In contrary, the structurally related tetra- and nodaviruses seem to interact more specifically with their ssRNA genome, since small RNA segments (Speir et al., 2010) or parts of the genome (Johnson et al., 2001) have been revealed even when the icosahedral symmetry has not been broken during the structure determination. This could explain why the comparison between CtenDNAV-II and the RNA viruses revealed different structural features of their capsids' interior, where the CtenDNAV-II was unmodelled and the ssRNA viruses had additional $\alpha$-helices (Fig. 3). A 7 nucleotide-stem loop gene fragment of the ssDNA geminivirus has been reported to interact with its capsid (Hesketh et al., 2018), which could indicate that not all ssDNA genomes are spooled.

The spooling genome structure is efficient for packaging long genomes of dsRNA and dsDNA viruses (Ilca et al., 2019; Liu and Cheng, 2015). The acquisition of the $\mathrm{T}=3$ capsid gene from a ssRNA virus could facilitate the packaging of a larger CRESS-DNA genome that cannot be accommodated by capsids of small $\mathrm{T}=1$ CRESS-DNA viruses (Kazlauskas et al., 2017). Many other ssDNA and dsDNA viruses such as animal tumor polyomaviruses and papillomaviruses, and plant geminiviruses are thought to be originated from primordial CRESS-DNA viruses (Kazlauskas et al., 2017; Koonin et al., 2015; Koonin and Dolja, 2014). Considering the polyphyletic origin of ssDNA viruses and their acquisitions of different RNA capsid proteins during the course of evolution, it will be interesting when future ssDNA virus structures are unravelled. 


\section{Materials and methods}

\section{Virus production and purification}

429 CtenDNAV-II was produced as previously described (Kimura and Tomaru, 2015). The crude virus suspension was loaded onto 15 to $50 \%(\mathrm{w} / \mathrm{v})$ sucrose density gradients and centrifuged at 24,000 $\times \operatorname{rpm}(102,170 \times \mathrm{g})$ for $18 \mathrm{~h}$ at $4^{\circ} \mathrm{C}(\mathrm{Sw} 40 \mathrm{Ti}$ rotor, Beckman Coulter). The fractions of the sucrose gradient were applied to SDS-PAGE. The VP2 capsid protein fractions were pooled and subjected to centrifugation at 28,000 rpm $(139,065 \times \mathrm{g})$ for $3 \mathrm{~h}$ at $4^{\circ} \mathrm{C}$ (Sw40Ti rotor, Beckman Coulter). The pellet was resuspended in $50 \mathrm{mM}$ Tris (pH 7.4), $100 \mathrm{mM} \mathrm{NaCl}$, and $0.1 \mathrm{mM}$ EDTA.

\section{Cryo-EM and data collection}

436 An aliquot $(3 \mu \mathrm{l})$ of purified CtenDNAV-II virons $\left(10 \mathrm{mg} \mathrm{ml}^{-1}\right)$ was deposited onto freshly glowdischarged holey carbon-coated copper grids (Quantifoil R 2/2, 300 mesh, copper) followed by $2 \mathrm{~s}$ of blotting in $100 \%$ relative humidity for plunge-freezing (Vitrobot Mark IV) in liquid ethane. Images were acquired using a Titan Krios microscope (Thermo Fisher Scientific) operated at $300 \mathrm{kV}$ and equipped with a K2 Summit direct electron detector (Gatan) and an energy filter.

\section{Image processing and 3D reconstruction}

442 The micrographs were corrected for beam-induced drift using MotionCor2 1.2.6 (Zheng et al., 2017), and contrast transfer function (CTF) parameters were estimated using Gctf 1.06 (Zhang, 2016). The RELION 3.1 package (Zivanov et al., 2018) was used for particle picking, 2D and 3D classifications, de novo 3D model generation and refinement. A reconstruction of the capsid was generated in $\mathrm{I} 4$ symmetry using 33,507 particles, which were obtained by performing 9 consecutive 2D classification steps. The two genome reconstructions were generated in $\mathrm{C} 1$ symmetry using 21,559 particles, which were generated by performing 6 consecutive 3D classifications of the 33,507 particles that were obtained from the 2D classification step. Resolutions were estimated using the gold standard Fourier shell correlation (threshold, 0.143 criterion) (Henderson et al., 2012; Scheres and Chen, 2012). The data set and image processing are summarized in Table 1.

To reconstruct the genome without icosahedral symmetry a similar procedure to what has been described by Ilca et al (Ilca et al., 2019) was carried out. The contribution of the capsid was first subtracted from the map created during the final iteration of the I4 refinement job using the Particle subtraction function in Relion. To create a mask for the particle subtraction, the capsid model was first transformed to a density map using the molmap command in Chimera and then an inverted soft edged mask was created from the density map using relion_mask_create with the --invert option. The subtraction was followed by 3D classification (C1 symmetry), which generated the subset of 21,559 particles that was used for the final $\mathrm{C} 1$ refinement. The $3 \mathrm{D}$ classifications revealed clear density of an outer layer, and an additional subtraction was therefore performed using a spherical mask of $100 \AA$ before the final refinement. The spherical mask was created using relion_mask_create with the -denovo and --outer_radius options. The two maps (the capsid density created by molmap and the circular map) were combined using Chimeras vop command before creating a new inverted mask using relion_mask_create, which was used for subtraction before the final 3D refinement. To reconstruct the core alone the spherical mask was used for the subtraction procedure.

\section{Model building and refinement}

467 The atomic model of CtenDNAV-II capsid protein was manually built into the density map using Coot (Emsley and Cowtan, 2004). The model was further improved through cycles of real-space refinement 
472 Chimera X (Goddard et al., 2018). Structural comparison of the CtenDNAV-II capsid protein was 473 carried out by the DALI server as a heuristic search against all structures (as of 2020-06-03) in the 474 PDB (Holm, 2020a).

\section{Data availability}

476 The atomic coordinates of CtenDNAV-II have been submitted to the Protein Data Bank under 477 accession no. 7NS0. The cryo-EM density maps of the CtenDNAV-II capsid and genome has been 478 deposited at the Electron Microscopy Data Bank under no. EMD-12554, 12555 and 12556, 479 respectively. 


\section{Acknowledgements}

481 The data were collected at the Cryo-EM Swedish National Facility funded by the Knut and Alice 482 Wallenberg, Erling Persson Family, and Kempe Foundations, SciLifeLab, Stockholm University and 483 Umeå University. We thank Julian Conrad and Dustin Morado for help with data collection. We also 484 want to thank Afonso Vieira for valuable discussions.

Funding was provided by the following agencies: Vetenskapsrådet (VR)/The Swedish Research Council (to K.O., grant no. 2018-03387), the Swedish Foundation for International Cooperation in 488 Research and Higher Education (STINT) (to Janos Hajdu and K.O., grant no. JA2014-5721), 489 FORMAS research grant from the Swedish Research Council for Environment, Agricultural Sciences, and Spatial Planning (to K.O., grant no. 2018-00421), the Royal Swedish Academy of Sciences (to 491 K.O., grant no. BS2018-0053), and the Japan Society for the Promotion of Science KAKENHI (to 492 Keizo Nagasaki, K.K., and Y.T., grant no. 16H06429, 16K21723, 16H06437, and 19H00956).

A.M., K.K., Y.T., and K.O. prepared the cryo-EM samples. A.M. and K.O. designed the experiments. A.M. and K.O. collected the cryo-EM data and analysed the data. H.W performed the HI assay. Y.T. performed the adsorption test. Y.H., K.Y., S.M. and K.K. performed the sequence analyses. A.M. and K.O. wrote the manuscript. All of the authors discussed the results and proofread the manuscript.

We declare no competing financial interests. 


\section{References}

501 Adams PD, Afonine PV, Bunkóczi G, Chen VB, Davis IW, Echols N, Headd JJ, Hung L-W, Kapral GJ, Grosse-Kunstleve RW, McCoy AJ, Moriarty NW, Oeffner R, Read RJ, Richardson DC, Richardson JS, Terwilliger TC, Zwart PH. 2010. PHENIX: a comprehensive Python-based system for macromolecular structure solution. Acta Crystallogr D Biol Crystallogr 66:213-221. doi:10.1107/S0907444909052925 Bratbak G, Egge JK, Heldal M. 1993. Viral mortality of the marine alga Emiliania huxleyi (Haptophyceae) and termination of algal blooms. Mar Ecol Prog Ser 93:39-48. Brussaard CPD. 2004. Viral Control of Phytoplankton Populations-a Review1. J Eukaryot Microbiol 51:125-138. doi:10.1111/j.1550-7408.2004.tb00537.x Chiba Y, Tomaru Y, Shimabukuro H, Kimura K, Hirai M, Takaki Y, Hagiwara D, Nunoura T, Urayama S. 2020. Viral RNA Genomes Identified from Marine Macroalgae and a Diatom. Microbes Environ 35:n/a. doi:10.1264/jsme2.ME20016

Coulibaly F, Chevalier C, Gutsche I, Pous J, Navaza J, Bressanelli S, Delmas B, Rey FA. 2005. The Birnavirus Crystal Structure Reveals Structural Relationships among Icosahedral Viruses. Cell 120:761-772. doi:10.1016/j.cell.2005.01.009

Dai X, Li Z, Lai M, Shu S, Du Y, Zhou ZH, Sun R. 2017. In situ structures of the genome and genome-delivery apparatus in a single-stranded RNA virus. Nature 541:112-116. doi:10.1038/nature20589 Diemer GS, Stedman KM. 2012. A novel virus genome discovered in an extreme environment suggests recombination between unrelated groups of RNA and DNA viruses. Biol Direct 7:13. doi:10.1186/1745-6150-7-13

Ding K, Celma CC, Zhang X, Chang T, Shen W, Atanasov I, Roy P, Zhou ZH. 2019. In situ structures of rotavirus polymerase in action and mechanism of mRNA transcription and release. Nat Commun 10:2216. doi:10.1038/s41467-019-10236-7

Dolja VV, Koonin EV. 2018. Metagenomics reshapes the concepts of RNA virus evolution by revealing extensive horizontal virus transfer. Virus Res 244:36-52. doi:10.1016/j.virusres.2017.10.020 Emsley P, Cowtan K. 2004. Coot : model-building tools for molecular graphics. Acta Crystallogr D Biol Crystallogr 60:2126-2132. doi:10.1107/S0907444904019158

Fuhrman JA. 1999. Marine viruses and their biogeochemical and ecological effects. Nature 399:541548. doi:10.1038/21119

Fulton JM, Fredricks HF, Bidle KD, Vardi A, Kendrick BJ, DiTullio GR, Van Mooy BAS. 2014. Novel molecular determinants of viral susceptibility and resistance in the lipidome of $E$ miliania huxleyi: Novel lipids in Emiliania huxleyi. Environ Microbiol 16:1137-1149. doi:10.1111/14622920.12358

Garriga D, Querol-Audí J, Abaitua F, Saugar I, Pous J, Verdaguer N, Castón JR, Rodriguez JF. 2006. The 2.6-Angstrom Structure of Infectious Bursal Disease Virus-Derived T=1 Particles Reveals New Stabilizing Elements of the Virus Capsid. J Virol 80:6895-6905. doi:10.1128/JVI.00368-06 Goddard TD, Huang CC, Meng EC, Pettersen EF, Couch GS, Morris JH, Ferrin TE. 2018. UCSF ChimeraX: Meeting modern challenges in visualization and analysis: UCSF ChimeraX Visualization System. Protein Sci 27:14-25. doi:10.1002/pro.3235

Gorzelnik KV, Cui Z, Reed CA, Jakana J, Young R, Zhang J. 2016. Asymmetric cryo-EM structure of the canonical Allolevivirus $\mathrm{Q} \beta$ reveals a single maturation protein and the genomic ssRNA in situ. Proc Natl Acad Sci 113:11519-11524. doi:10.1073/pnas.1609482113

Harrison SC, Olson AJ, Schutt CE, Winkler FK, Bricogne G. 1978. Tomato bushy stunt virus at $2.9 \AA$ resolution. Nature 276:368-373. doi:10.1038/276368a0

Helgstrand C, Munshi S, Johnson JE, Liljas L. 2004. The refined structure of Nudaurelia capensis $\omega$ Virus reveals control elements for a $T=4$ capsid maturation. Virology 318:192-203. doi:10.1016/j.virol.2003.08.045

Henderson R, Sali A, Baker ML, Carragher B, Devkota B, Downing KH, Egelman EH, Feng Z, Frank J, Grigorieff N, Jiang W, Ludtke SJ, Medalia O, Penczek PA, Rosenthal PB, Rossmann MG, Schmid MF, Schröder GF, Steven AC, Stokes DL, Westbrook JD, Wriggers W, Yang H, Young J, Berman HM, Chiu W, Kleywegt GJ, Lawson CL. 2012. Outcome of the First Electron Microscopy Validation Task Force Meeting. Structure 20:205-214. doi:10.1016/j.str.2011.12.014 

structure of a plant geminivirus using cryo-EM. Nat Commun 9:2369. doi:10.1038/s41467-018-047936

Ho KL, Gabrielsen M, Beh PL, Kueh CL, Thong QX, Streetley J, Tan WS, Bhella D. 2018. Structure of the Macrobrachium rosenbergii nodavirus: A new genus within the Nodaviridae? PLOS Biol 16:e3000038. doi:10.1371/journal.pbio.3000038 Holm L. 2020a. DALI and the persistence of protein shape. Protein Sci 29:128-140. doi:10.1002/pro.3749 Holm L. 2020b. Using Dali for Protein Structure Comparison In: Gáspári Z, editor. Structural Bioinformatics, Methods in Molecular Biology. New York, NY: Springer US. pp. 29-42. doi:10.1007/978-1-0716-0270-6 3 Hulo C, de Castro E, Masson P, Bougueleret L, Bairoch A, Xenarios I, Le Mercier P. 2011. ViralZone: a knowledge resource to understand virus diversity. Nucleic Acids Res 39:D576-D582. doi:10.1093/nar/gkq901

Ilca SL, Sun X, El Omari K, Kotecha A, de Haas F, DiMaio F, Grimes JM, Stuart DI, Poranen MM, Huiskonen JT. 2019. Multiple liquid crystalline geometries of highly compacted nucleic acid in a dsRNA virus. Nature 570:252-256. doi:10.1038/s41586-019-1229-9 Inoue T, Tsai B. 2011. A Large and Intact Viral Particle Penetrates the Endoplasmic Reticulum Membrane to Reach the Cytosol. PLoS Pathog 7:e1002037. doi:10.1371/journal.ppat.1002037 Johannessen T, Larsen A, Bratbak G, Pagarete A, Edvardsen B, Egge E, Sandaa R-A. 2017. Seasonal Dynamics of Haptophytes and dsDNA Algal Viruses Suggest Complex Virus-Host Relationship. Viruses 9:84. doi:10.3390/v9040084

Johnson JE, Tang L, Johnson KN, Ball LA, Lin T, Yeager M. 2001. The structure of Pariacoto virus reveals a dodecahedral cage of duplex RNA. Nat Struct Biol 8:77-83. doi:10.1038/83089

Kazlauskas D, Dayaram A, Kraberger S, Goldstien S, Varsani A, Krupovic M. 2017. Evolutionary history of ssDNA bacilladnaviruses features horizontal acquisition of the capsid gene from ssRNA nodaviruses. Virology 504:114-121. doi:10.1016/j.virol.2017.02.001

Kazlauskas D, Varsani A, Koonin EV, Krupovic M. 2019. Multiple origins of prokaryotic and eukaryotic single-stranded DNA viruses from bacterial and archaeal plasmids. Nat Commun 10:3425. doi:10.1038/s41467-019-11433-0 Kimura K, Tomaru Y. 2015. Discovery of Two Novel Viruses Expands the Diversity of SingleStranded DNA and Single-Stranded RNA Viruses Infecting a Cosmopolitan Marine Diatom. Appl Environ Microbiol 81:1120-1131. doi:10.1128/AEM.02380-14

Koning RI, Gomez-Blanco J, Akopjana I, Vargas J, Kazaks A, Tars K, Carazo JM, Koster AJ. 2016. Asymmetric cryo-EM reconstruction of phage MS2 reveals genome structure in situ. Nat Commun 7:12524. doi: $10.1038 /$ ncomms 12524

Koonin EV, Dolja VV. 2014. Virus World as an Evolutionary Network of Viruses and Capsidless Selfish Elements. Microbiol Mol Biol Rev 78:278-303. doi:10.1128/MMBR.00049-13

Koonin EV, Dolja VV, Krupovic M. 2015. Origins and evolution of viruses of eukaryotes: The ultimate modularity. Virology 479-480:2-25. doi:10.1016/j.virol.2015.02.039

Krupovic M. 2013. Networks of evolutionary interactions underlying the polyphyletic origin of ssDNA viruses. Curr Opin Virol 3:578-586. doi:10.1016/j.coviro.2013.06.010 Krupovic M, Koonin EV. 2017. Multiple origins of viral capsid proteins from cellular ancestors. Proc Natl Acad Sci U S A 114:E2401-E2410. doi:10.1073/pnas.1621061114

Krupovic M, Varsani A, Kazlauskas D, Breitbart M, Delwart E, Rosario K, Yutin N, Wolf YI, Harrach B, Zerbini FM, Dolja VV, Kuhn JH, Koonin EV. 2020. Cressdnaviricota : a Virus Phylum Unifying Seven Families of Rep-Encoding Viruses with Single-Stranded, Circular DNA Genomes. $J$ Virol 94:e00582-20, /jvi/94/12/JVI.00582-20.atom. doi:10.1128/JVI.00582-20

Kucukelbir A, Sigworth FJ, Tagare HD. 2014. Quantifying the local resolution of cryo-EM density maps. Nat Methods 11:63-65. doi:10.1038/nmeth.2727

Laanto E, Mäntynen S, De Colibus L, Marjakangas J, Gillum A, Stuart DI, Ravantti JJ, Huiskonen JT, Sundberg L-R. 2017. Virus found in a boreal lake links ssDNA and dsDNA viruses. Proc Natl Acad Sci 114:8378-8383. doi:10.1073/pnas.1703834114 Liu H, Cheng L. 2015. Cryo-EM shows the polymerase structures and a nonspooled genome within a dsRNA virus. Science 349:1347-1350. doi:10.1126/science.aaa4938 
Liu W, Hsu C-H, Hong Y-R, Wu S-C, Wang C-H, Wu Y-M, Chao C-B, Lin C-S. 2005. Early endocytosis pathways in SSN-1 cells infected by dragon grouper nervous necrosis virus. $J$ Gen Virol 86:2553-2561. doi:10.1099/vir.0.81021-0 Liu Y-T, Jih J, Dai X, Bi G-Q, Zhou ZH. 2019. Cryo-EM structures of herpes simplex virus type 1 portal vertex and packaged genome. Nature 570:257-261. doi:10.1038/s41586-019-1248-6 Mallery DL, Márquez CL, McEwan WA, Dickson CF, Jacques DA, Anandapadamanaban M, Bichel K, Towers GJ, Saiardi A, Böcking T, James LC. 2018. IP6 is an HIV pocket factor that prevents capsid collapse and promotes DNA synthesis. eLife 7. doi:10.7554/eLife.35335 Moreno P, Souto S, Leiva-Rebollo R, Borrego JJ, Bandín I, Alonso MC. 2019. Capsid amino acids at positions 247 and 270 are involved in the virulence of betanodaviruses to European sea bass. Sci Rep 9:14068. doi:10.1038/s41598-019-50622-1 Muhire BM, Golden M, Murrell B, Lefeuvre P, Lett J-M, Gray A, Poon AYF, Ngandu NK, Semegni Y, Tanov EP, Monjane AL, Harkins GW, Varsani A, Shepherd DN, Martin DP. 2014. Evidence of Pervasive Biologically Functional Secondary Structures within the Genomes of Eukaryotic SingleStranded DNA Viruses. J Virol 88:1972-1989. doi:10.1128/JVI.03031-13 Munke A, Kimura K, Tomaru Y, Okamoto K. 2020. Capsid Structure of a Marine Algal Virus of the Order Picornavirales. J Virol 94:e01855-19, /jvi/94/9/JVI.01855-19.atom. doi:10.1128/JVI.01855-19 Nagasaki K, Shirai Y, Takao Y, Mizumoto H, Nishida K, Tomaru Y. 2005. Comparison of genome sequences of single-stranded RNA viruses infecting the bivalve-killing dinoflagellate Heterocapsa circularisquama. Appl Environ Microbiol 71:8888-8894. doi:10.1128/AEM.71.12.8888-8894.2005 Nagasaki K, Tarutani K, Yamaguchi M. 1999. Growth Characteristics of $<$ em $>$ Heterosigma akashiwo $</ \mathrm{em}>$ Virus and Its Possible Use as a Microbiological Agent for Red Tide Control. Appl Environ Microbiol 65:898. Ng TFF, Zhang W, Sachsenröder J, Kondov NO, da Costa AC, Vega E, Holtz LR, Wu G, Wang D, Stine CO, Antonio M, Mulvaney US, Muench MO, Deng X, Ambert-Balay K, Pothier P, Vinjé J, Delwart E. 2015. A diverse group of small circular ssDNA viral genomes in human and non-human primate stools. Virus Evol 1:vev017. doi:10.1093/ve/vev017

Nishihara T, Kurano N, Shinoda S. 1986. Calculation of Most Probable Number for Enumeration of Bacteria on a Micro-Computer. Eisei Kagaku 32:226-228. doi:10.1248/jhs1956.32.226

Okamoto K, Ferreira RJ, Larsson DSD, Maia FRNC, Isawa H, Sawabe K, Murata K, Hajdu J, Iwasaki K, Kasson PM, Miyazaki N. 2020. Acquired Functional Capsid Structures in Metazoan Totivirus-like dsRNA Virus. Structure 28:888-896.e3. doi:10.1016/j.str.2020.04.016

Okamoto K, Miyazaki N, Larsson DSD, Kobayashi D, Svenda M, Mühlig K, Maia FRNC, Gunn LH, Isawa H, Kobayashi M, Sawabe K, Murata K, Hajdu J. 2016. The infectious particle of insect-borne totivirus-like Omono River virus has raised ridges and lacks fibre complexes. Sci Rep 6:33170. doi:10.1038/srep33170

Penkler DL, Jiwaji M, Domitrovic T, Short JR, Johnson JE, Dorrington RA. 2016. Binding and entry of a non-enveloped $\mathrm{T}=4$ insect RNA virus is triggered by alkaline $\mathrm{pH}$. Virology 498:277-287. doi:10.1016/j.virol.2016.08.028

Pettersen EF, Goddard TD, Huang CC, Couch GS, Greenblatt DM, Meng EC, Ferrin TE. 2004. UCSF Chimera?A visualization system for exploratory research and analysis. J Comput Chem 25:16051612. doi: $10.1002 / j c c .20084$ Phan TG, Mori D, Deng X, Rajindrajith S, Ranawaka U, Fan Ng TF, Bucardo-Rivera F, Orlandi P, Ahmed K, Delwart E. 2015. Small circular single stranded DNA viral genomes in unexplained cases of human encephalitis, diarrhea, and in untreated sewage. Virology 482:98-104. doi:10.1016/j.virol.2015.03.011

Rossmann MG, Arnold E, Erickson JW, Frankenberger EA, Griffith JP, Hecht H-J, Johnson JE, Kamer G, Luo M, Mosser AG, Rueckert RR, Sherry B, Vriend G. 1985. Structure of a human common cold virus and functional relationship to other picornaviruses. Nature 317:145-153. doi: $10.1038 / 317145 \mathrm{a} 0$ Scheres SHW. 2012. RELION: Implementation of a Bayesian approach to cryo-EM structure determination. J Struct Biol 180:519-530. doi:10.1016/j.jsb.2012.09.006 Scheres SHW, Chen S. 2012. Prevention of overfitting in cryo-EM structure determination. Nat Methods 9:853-854. doi:10.1038/nmeth.2115 
Speir JA, Taylor DJ, Natarajan P, Pringle FM, Ball LA, Johnson JE. 2010. Evolution in Action: N and $\mathrm{C}$ Termini of Subunits in Related T $=4$ Viruses Exchange Roles as Molecular Switches. Structure 18:700-709. doi:10.1016/j.str.2010.03.010 Ströh LJ, Rustmeier NH, Blaum BS, Botsch J, Rößler P, Wedekink F, Lipkin WI, Mishra N, Stehle T. 2020. Structural Basis and Evolution of Glycan Receptor Specificities within the Polyomavirus Family. mBio 11:e00745-20, /mbio/11/4/mBio.00745-20.atom. doi:10.1128/mBio.00745-20 Suttle CA. 2007. Marine viruses - major players in the global ecosystem. Nat Rev Microbiol 5:801812. doi:10.1038/nrmicro 1750

671 Suttle CA. 1993. Enumeration and isolation of virusesHandbook of Methods in Aquatic Microbial 672 Ecology. Boca Raton: Lewis Publishers.

673 Tarutani K, Nagasaki K, Yamaguchi M. 2006. Virus adsorption process determines virus 674 susceptibility in Heterosigma akashiwo (Raphidophyceae). Aquat Microb Ecol 42:209-213. 675 doi:10.3354/ame042209

676 Tarutani K, Nagasaki K, Yamaguchi M. 2000. Viral Impacts on Total Abundance and Clonal Composition of the Harmful Bloom-Forming PhytoplanktonHeterosigma akashiwo. Appl Environ Microbiol 66:4916-4920. doi:10.1128/AEM.66.11.4916-4920.2000

Tisza MJ, Pastrana DV, Welch NL, Stewart B, Peretti A, Starrett GJ, Pang Y-YS, Krishnamurthy SR, Pesavento PA, McDermott DH, Murphy PM, Whited JL, Miller B, Brenchley J, Rosshart SP, Rehermann B, Doorbar J, Ta'ala BA, Pletnikova O, Troncoso JC, Resnick SM, Bolduc B, Sullivan MB, Varsani A, Segall AM, Buck CB. 2020. Discovery of several thousand highly diverse circular DNA viruses. eLife 9:e51971. doi:10.7554/eLife.51971

Tomaru Y, Kimura K. 2016. Rapid quantification of viable cells of the planktonic diatom Chaetoceros tenuissimus and associated RNA viruses in culture. Plankton Benthos Res 11:9-16. doi:10.3800/pbr.11.9

Tomaru Y, Shirai Y, Toyoda K, Nagasaki K. 2011. Isolation and characterisation of a single-stranded DNA virus infecting the marine planktonic diatom Chaetoceros tenuissimus. Aquat Microb Ecol 64:175-184. doi:10.3354/ame01517

Tomaru Y, Toyoda K, Suzuki H, Nagumo T, Kimura K, Takao Y. 2013. New single-stranded DNA virus with a unique genomic structure that infects marine diatom Chaetoceros setoensis. Sci Rep 3:3337. doi:10.1038/srep03337

Wagstaff BA, Rejzek M, Field RA. 2018. Identification of a Kdn biosynthesis pathway in the haptophyte Prymnesium parvum suggests widespread sialic acid biosynthesis among microalgae. $J$ Biol Chem 293:16277-16290. doi:10.1074/jbc.RA118.004921

Wang F, Liu Y, Su Z, Osinski T, de Oliveira GAP, Conway JF, Schouten S, Krupovic M, Prangishvili D, Egelman EH. 2019. A packing for A-form DNA in an icosahedral virus. Proc Natl Acad Sci 116:22591-22597. doi:10.1073/pnas.1908242116 Wang X, Zhang F, Su R, Li X, Chen W, Chen Q, Yang T, Wang J, Liu H, Fang Q, Cheng L. 2018. Structure of RNA polymerase complex and genome within a dsRNA virus provides insights into the mechanisms of transcription and assembly. Proc Natl Acad Sci 115:7344-7349.

doi:10.1073/pnas.1803885115

Wilhelm SW, Suttle CA. 1999. Viruses and Nutrient Cycles in the Sea. BioScience 49:781-788. doi:10.2307/1313569

Wolf YI, Silas S, Wang Y, Wu S, Bocek M, Kazlauskas D, Krupovic M, Fire A, Dolja VV, Koonin EV. 2020. Doubling of the known set of RNA viruses by metagenomic analysis of an aquatic virome. Nat Microbiol 5:1262-1270. doi:10.1038/s41564-020-0755-4 Zhang K. 2016. Gctf: Real-time CTF determination and correction. J Struct Biol 193:1-12. doi:10.1016/j.jsb.2015.11.003

Zhang X, Ding K, Yu X, Chang W, Sun J, Hong Zhou Z. 2015. In situ structures of the segmented genome and RNA polymerase complex inside a dsRNA virus. Nature 527:531-534. doi:10.1038/nature15767

Zheng SQ, Palovcak E, Armache J-P, Verba KA, Cheng Y, Agard DA. 2017. MotionCor2: anisotropic correction of beam-induced motion for improved cryo-electron microscopy. Nat Methods 14:331-332. doi: $10.1038 /$ nmeth.4193 
716 Zivanov J, Nakane T, Forsberg BO, Kimanius D, Hagen WJ, Lindahl E, Scheres SH. 2018. New tools 717 for automated high-resolution cryo-EM structure determination in RELION-3. eLife 7:e42166.

718 doi:10.7554/eLife.42166

719 Zocher G, Mistry N, Frank M, Hähnlein-Schick I, Ekström J-O, Arnberg N, Stehle T. 2014. A Sialic 720 Acid Binding Site in a Human Picornavirus. PLoS Pathog 10:e1004401.

721 doi:10.1371/journal.ppat.1004401 


\section{Supplementary figures}
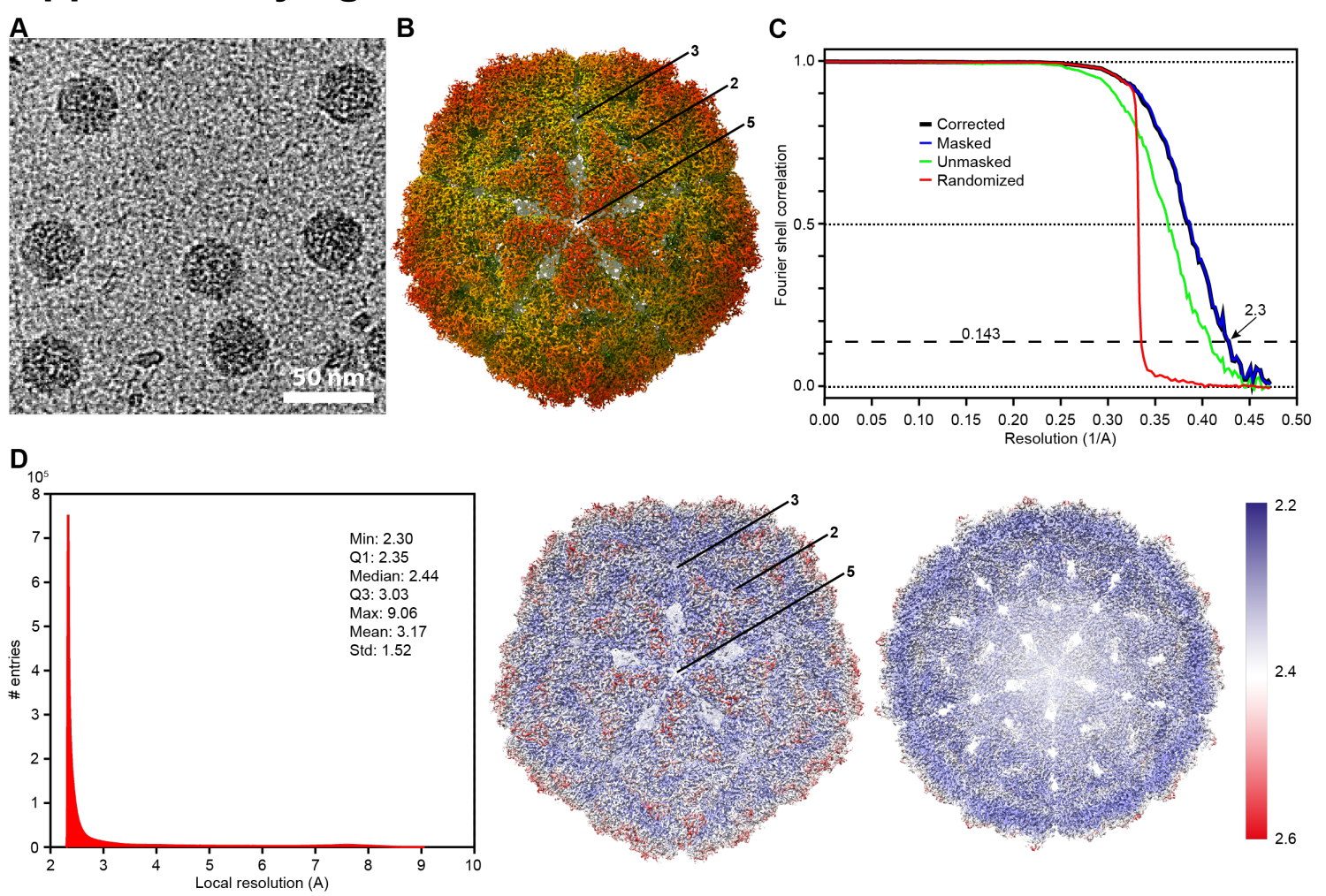

Supplementary Figure 1. Data collection and reconstruction of the capsid. (A) Cryo-EM raw image of CtenDNAV-II. (B) Cryo-EM 3D reconstruction of the CtenDNAV-II capsid. The capsid is viewed down the five-fold axis and radially coloured from blue to red. The icosahedral five-fold, three-fold, and two-fold axes are labelled as 5, 3, and 2, respectively. (C) The gold standard FSC resolution curves of masked (blue) and unmasked (green) reconstructions of the CtenDNAV-II capsid. Possible effects of the masking were compensated for by noise randomization (red), to create the final FSC curve (black). The resolution at which the correlation drops below the $\mathrm{FSC}=0.143$ (gold standard threshold (Henderson et al., 2012; Scheres and Chen, 2012) is $2.3 \AA$. (D) Local resolution of the final reconstruction determined by Relion. The left panel shows a histogram of the local resolution, and the middle and right panel shows the reconstruction coloured from red to white to blue that corresponds to local resolutions 2.6, 2.4 and 2.2, respectively. The icosahedral five-fold, three-fold, and two-fold axes are labelled as 5, 3, and 2, respectively in the middle panel. The front half of the reconstruction is removed in the right most panel to visualize the inside of the capsid.

A

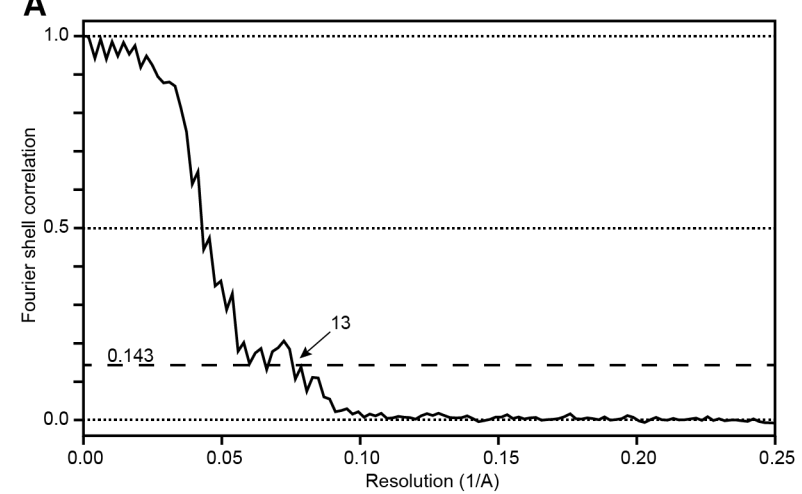

B

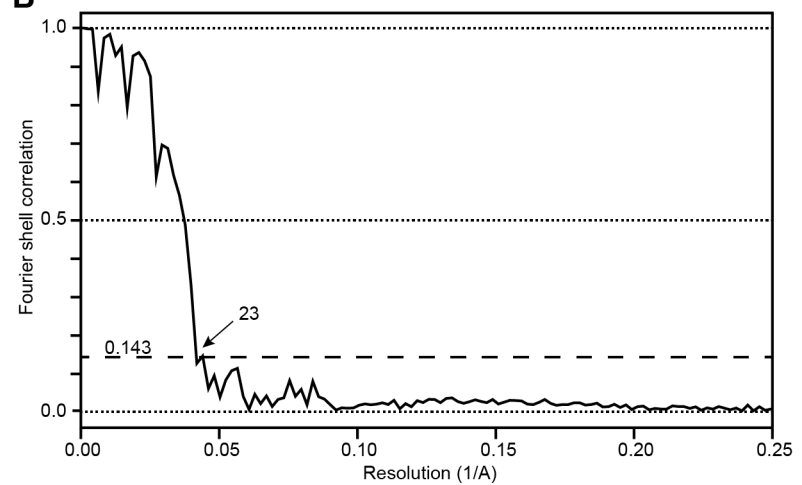

740 Supplementary Figure 2. The gold standard FSC resolution curves of the asymmetric 


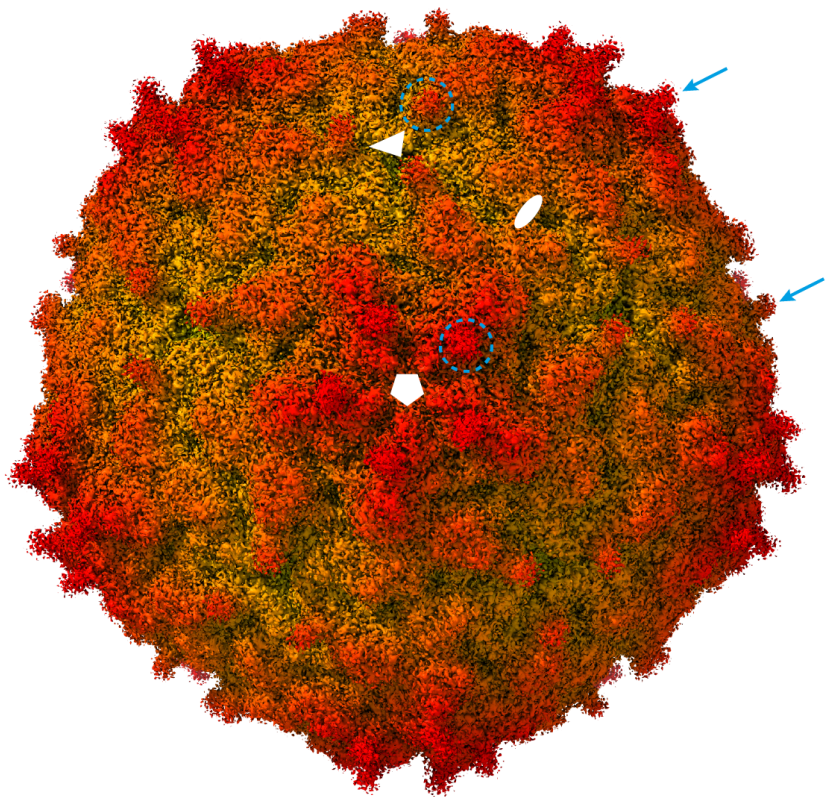

Supplementary Figure 2. Cryo-EM 3D reconstruction of the CtenDNAV-II capsid at low contour level. Unmodelled densities around the three- and five-fold axes are indicated with blue arrows and circles, which correspond to the $\mathrm{C}$-terminal ends of subunit $\mathrm{A}$ and $\mathrm{B}$. The capsid is viewed down the five-fold axis and radially coloured from blue to red. The positions of the five-, three-, and two-fold axes are shown by a white pentamer, triangle, and ellipse, respectively.
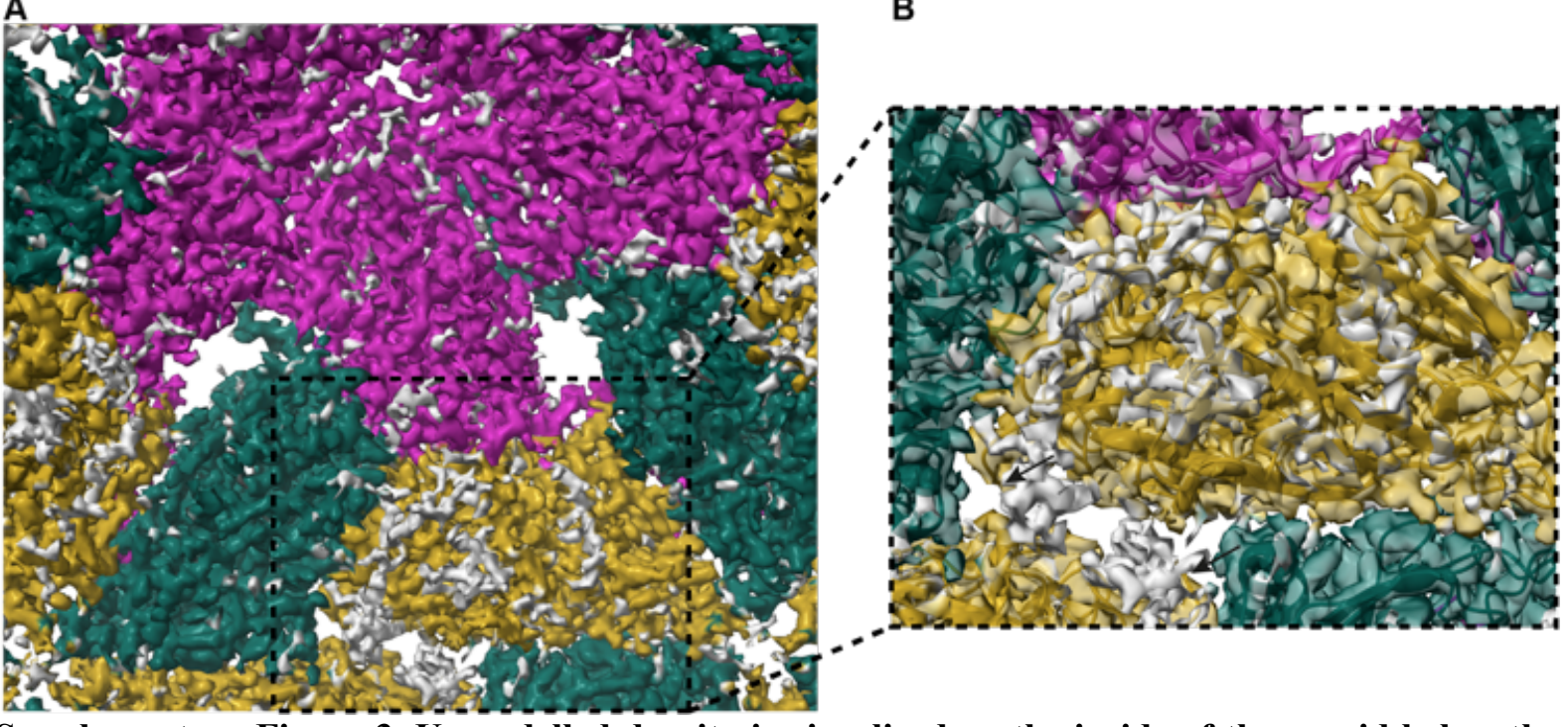
three subunits. By decreasing the contour level, unmodelled densities are visualized in grey. (B) Close-up view of the $\mathrm{C}$ subunit, where the reconstruction is transparent to reveal the model in ribbon representation. The last modelled residues in the C-termini of the two 2-fold symmetry related $\mathrm{C}$ subunits are indicated with black arrows. 
756

757

758

759

760

761

762

763

764

765

766

767

768

769

770

771

772

773

774

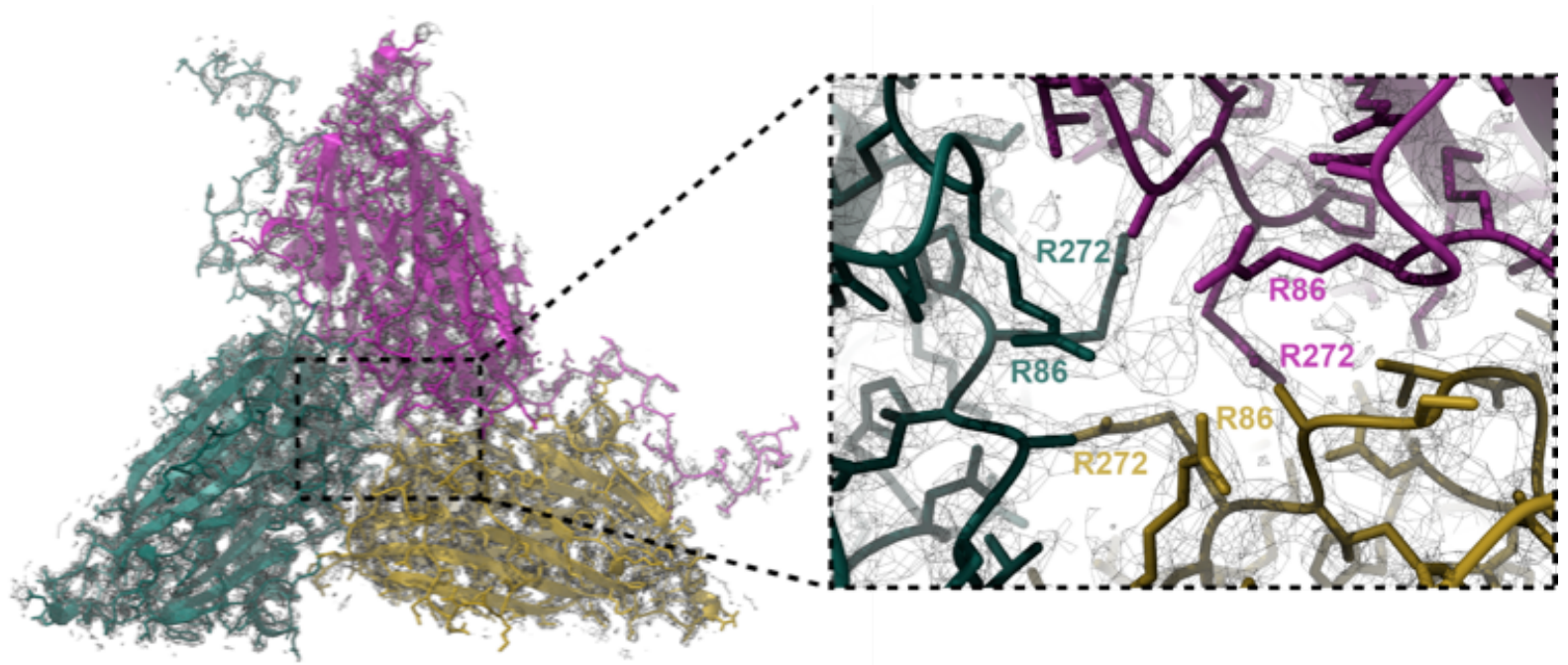

Supplementary Figure 4. Putative ion located in the subunit interface. The model of a single icosahedral protomer viewed from the inside of the capsid and corresponding cryo-EM map is visualized to the left. To the right, is a close-up view of the subunit interface, displaying density in the centre possibly originating from an ion and the surrounding arginine residues.

A
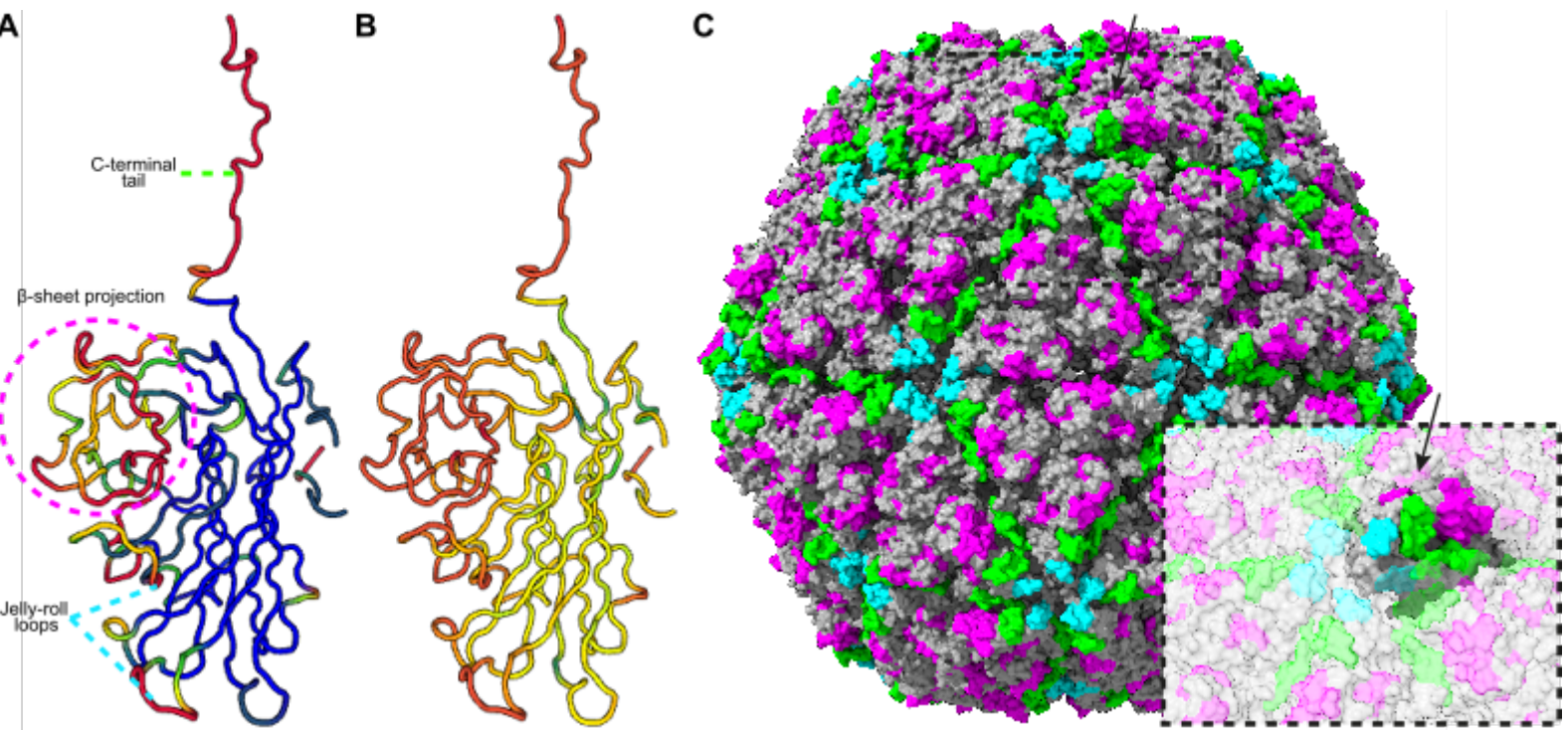

Supplementary Figure 5. Superimposition performed by the DALI server of the CtenDNAV-II capsid protein against corresponding capsid proteins from viruses in Fig. 3B. The figures show CtenDNAV-II subunit A coloured according to (A) structural conservation and (B) sequence conservation where conservation mapping goes from blue for the highest values through green to red for the lowest values. (A) The three areas where structural conservation has the lowest values; the Cterminal tail, $\beta$-sheet projection, and jelly-roll loops C'-C"' and H-I are highlighted in green, magenta and cyan dashed lines. $(\mathbf{C})$ The entire capsid rendered with a surface representation viewed down an icosahedral two-fold axis. The amino acids with lowest structural conservation (red in panel A) are coloured green, magenta and cyan that corresponds to the areas $\mathrm{N}$-terminal tail, $\beta$-sheet projection and jelly-roll loops labelled in (A). The insert is zooming in on one of the five-folds and highlights one Asubunit and the C-terminus (green) coming from the B-subunit in an adjacent five-fold related protomer. 
Strain SS10V-8V 2-6 $11 \mathrm{~V} 10$ 2-6_11V12 2-6_10V07 2-6_10V05 2-6_10V17 2-6_10V20 SS10V-24V 2-6_10V27 2-6_10V33 2-6_11V04 2-6_11V08 2-6_11V06 2-6_11V17

PDGRMLESLP RRCQLVTEIR NNVTVGSNPT YILVAPSLGL AFQAYQDTNV PGGLDSSVYG

777

\section{Strain}

IONRGCTVRA NTSATSTFNY NDIAKWRTVS OGTNTKTNV FDFNDGWYFA CRFOHDWTPD FTCTRSTEND

\section{SS10V-8V}

SS10V-35V

2-6 $11 \mathrm{~V} 10$

$2-6-11 \mathrm{~V} 12$

$2-6-10 \mathrm{~V} 07$

2-6_10V05

$2-6$ - $10 \mathrm{~V} 17$

$2-6-10 \mathrm{~V} 20$

SS10V-24V

2-6 $10 \mathrm{~V} 27$

$2-6+10 \mathrm{~V} 33$

2-6-11V04

$2-6-11 \mathrm{~V} 08$

2-6 $11 \mathrm{~V} 06$

2-6_11V17
IIIIIIIIII IIIIIIIIII IIIIIIIIII IIIIIIIIII IIIIIIIIII IIIIIIIIII

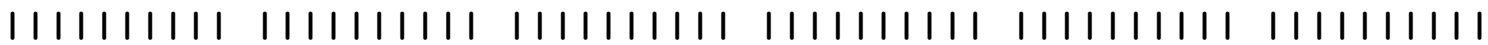

IIIIIIIIII IIIIIIIIII IIIIIIIIII IIIIIIIIII IIIIIIIIII IIIIIIIIII

1111111111,11111111111111111111111111111111111111111111111111

IIIIIIIIII IIIIIIIIII IIIIIIIIII IIIIIIIIII IIIIIIIIII IIIIIIIIII

1111111111 1IIIIIIIII IIIIIIIIII IIIIIIIIII IIIIIIIIII IIIIIIIIII

1111111111 1IIIIIIIII IIIIIIIIII IIIIIIIIII IIIIIIIIII IIIIIIIIII

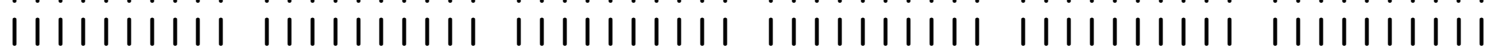

IIIIIIIIII IIIIIIIIII IIIIIIIIII IIIIIIIIII IIIIIIIIII IIIIIIIIII

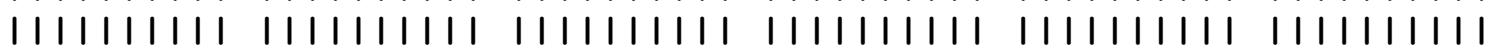

1111111111,11111111111111111111111111111111111111111111111111

IIIIIIIIII IIIIIIIIII IIIIIIIIII IIIIIIIIII IIIIIIIIII IIIIIIIIII

IIIIIIIIII IIIIIIIIII IIIIIIIIII IIIIIIIIII IIIIIIIIII IIIIIIIIII

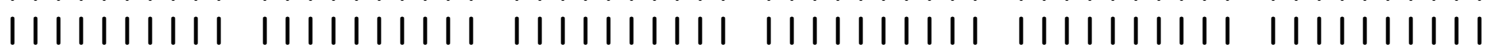

LQNRGCTVRA NLSATSIENY NDIAKWRIVS QGINLKLNNV EDENDGWYEA CREQHDWTPD ELCLRSTEND

IIIIIIIII IIIIIIIII IIIIIIIII IIIIIIIII IIIIIIIII IIIIIIIII IIIIIIIII

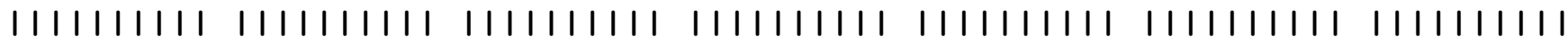

1111111111 1IIIIIIIII IIIIIIIIII IIIIIIIIII IIIIIIIIII IIIIIIIIII IIIIIIIIII

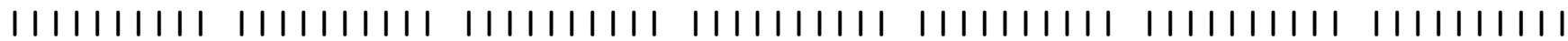

IIIIIIIIII IIIIIIIIII IIIIIIIIII IIIIIIIIII IIIIIIIIII IIIIIIIIII IIIIIIIIII

IIIIIIIIII IIIIIIIIII IIIIIIIIII IIIIIIIIII IIIIIIIIII IIIIIIIIII IIIIIIIIII

IIIIIIIIII IIIIIIIIII IIIIIIIIII IIIIIIIIII IIIIIIIIII IIIIIIIIII IIIIIIIII

IIIIIIIIII IIIIIIIIII IIIIIIIIII IIIIIIIIII IIIIIIIIII IIIIIIIIII IIIIIIIIII

1111111111 1IIIIIIIII IIIIIIIIII IIIIIIIIII IIIIIIIIII IIIIIIIIII IIIIIIIIII

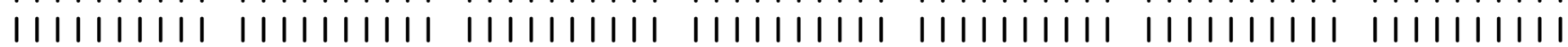

IIIIIIIIII IIIIIIIIII IIIIIIIIII IIIIIIIIII IIIIIIIIII IIIIIIIIII IIIIIIIIII

IIIIIIIIII IIIIIIIIII IIIIIIIII IIIIIIIIII IIIIIIIIII IIIIIIIIII IISIIIIIII

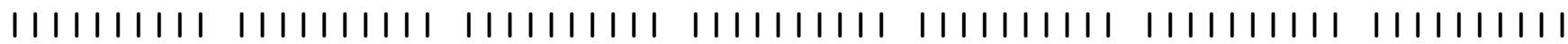

IIIIIIIIII IIIIIIIIII IIIIIIIIII IIIIIIIIII IIIIIIIIII IIIIIIIIII IIIIIIIIII 


\begin{tabular}{|c|c|c|c|c|c|c|c|}
\hline Strain & ASTISQDEDL & VMGVISSSFL & NGALNTIGNN & MVEQRGYESG & LLKNIHKRMF & QLHNNTSAIR & PKTLQGQFNY \\
\hline SS10V-8V & $\|1\|\|\|\|\| \|$ & \|\|\|\|\|\|$M$ & $|\|||||||| \mid$ & $\mid\|\|\|\|\|\|$ & $|1| 1111111$ & 1111111111 & 1111111111 \\
\hline SS10V-35V & 111 & $11 \mathrm{~s}$ & |||||||||| & $|1||||||| \mid$ & $1|1|||||||$ & |||||||||| & | | | \\
\hline 2-6_11V10 & 1111111111 & 1111111111 & 1111111111 & 1111111111 & 1111111111 & $111|1| 1 \mid$ & 11111 \\
\hline $2-6 \_11 \mathrm{~V} 12$ & |||||||||| & $|1||||||| \mid$ & $1|1|||||||$ & $111|1||| 1 \mid$ & $|1||||||| \mid$ & |||| $\mid$ & $|1||||||| \mid$ \\
\hline 2-6_10V07 & 1111111111 & 1111111111 & 1111111111 & 1111111111 & $111|1| 1|1|$ & $111|1| 1|1|$ & 11111 \\
\hline 2-6_10V05 & $\|1\|$ & & & & & & \\
\hline 2-6_10V17 & TNN I I & & & & & & \\
\hline 2-6_10V20 & |||| $\mid$ & | | | & 111 & & 111 & 111 & \\
\hline SS10V-24V & $T\|\|$ & 1111 & $|1||||||| \mid$ & I & |||| $\mid$ & |||||||||| & 1 \\
\hline 2-6_10V27 & |||| $\mid$ & III & $|1||||||| \mid$ & 111111 & $|1||||||| \mid$ & $|1||||||| \mid$ & 11111 \\
\hline 2-6_10V33 & $111|1| 1|| 1$ & $|1||||||| \mid$ & |||||||||| & $|1||||||| \mid$ & $11|1||||| \mid$ & $111|1||| 1 \mid$ & 11111111111 \\
\hline 2-6_11V04 & 1111111111 & $|1||||||| \mid$ & 1111111111 & 1111111111 & 1111111111 & 1111111111 & |||| \\
\hline 2-6_11V08 & $|N S|||||||$ & $111|1| 1|1|$ & $1111|1| 1|1|$ & & & & \\
\hline 2-6_11V06 & & & & & & & \\
\hline 2-6_11V17 & 11111111 & 1111111111 & |||||||||| & & 1111111111 & 1111111111 & 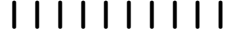 \\
\hline
\end{tabular}

\begin{tabular}{|c|c|c|c|c|c|c|c|}
\hline Strain & GSEITFSGTE & SEARFTDVPS & NRQLVDSLWH & NDYDCILIKL & YPRENTGAAG & QTGSALIVNA & IQNLELQYSP \\
\hline SS10V-8V & \|\|\|\|\|\|$\|$ & 1111111111 & $|1||||||| \mid$ & $111\|1\| 1\|1\|$ & 11\|\|\|\|$\| \mid$ & 11\|\|\|\|\|\| & 1111111111 \\
\hline SS10V-35V & & 111 & & & $|1||||||| \mid$ & & |||||||| $\mid$ \\
\hline 2-6_11V10 & |||||| $\mid$ & 111 & 111 & 1 & $|1||||||| \mid$ & R|AKRPHCKR & YSKFGAAIFS \\
\hline 2-6_11V12 & $|1||||||| \mid$ & $|1||||||| \mid$ & 111 & 1111 & $1|1| 1|1| 1 \mid$ & $R\|\|\|\|\|\|$ & $|1||||||| \mid$ \\
\hline $2-6$ - 10 V07 & $|1||||||| \mid$ & $N|||||||| \mid$ & $|1||||||| \mid$ & $|1||||||| \mid$ & 11|||||||| & $|1||||||| \mid$ & $|1||||||| \mid$ \\
\hline 2-6_10V05 & $|1||||||| \mid$ & $N\|\|\|\|\|\|$ & |||||||||| & $11|1||| 1 \mid 1$ & $|1||||||| \mid$ & | || || & |||| \\
\hline 2-6_10V17 & & 11111111 & & & & & \\
\hline 2-6_10V20 & & NII & & & 111 & 111 & I \\
\hline SS10V-24V & |||||| $\mid$ & $|1||||||| \mid$ & 111 & & $|1||||||| \mid$ & $|1|||$ & |1 | \\
\hline 2-6_10V27 & |||||||||| & $|1||||||| \mid$ & $|1||||||| \mid$ & 11111 & $111|1||1| 1$ & $|1||||||| \mid$ & || | \\
\hline 2-6_10V33 & 1111111111 & $N\|\|\|\|\|\|$ & 1111111111 & 11111 & 1111111111 & 1111111111 & |||||||| $\mid$ \\
\hline 2-6_11V04 & \|\|$\|I\|\|\|$ & |||||||||| & |||||||||| & |||||||||| & |||||||||| & | |AKRPHCKR & YSKFGAAIFS \\
\hline 2-6_11V08 & \|\| $\mid I\|\| \|$ & 1111111111 & 1111111111 & 1111111111 & 1111111111 & 1111111111 & 1111111111 \\
\hline 2-6_11V06 & 1111 & $|1||||| \mid$ & & & & & \\
\hline & & & & & & & \\
\hline
\end{tabular}




\begin{tabular}{|c|c|c|c|c|}
\hline Strain & TSDLSTYHIA & NKRARMVEAK & LDKKNNTDAA & GEPFVPGSSR* \\
\hline SS10V-8V & 1111111111 & 1111111111 & 1111111111 & \|\|\|\|\|\|$\|^{*}$ \\
\hline SS10V-35V & $\|1\| 1\|\|\|\|$ & $|\|||||||| \mid$ & |||||||||| & \|\|\|\|\|\|$\|^{*}$ \\
\hline 2-6_11V10 & & & & \\
\hline 2-6_11V12 & 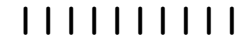 & |||||||||| & \|\|\|\|$\|$ & |||T* \\
\hline $2-6$ & & & & 11 * \\
\hline 2-6_10V05 & 111 & 111 & 111 & $|1| *$ \\
\hline 2-6_10V17 & $11\|1\| 1\|1\| 1$ & ||||$K|G|||$ & \|\|\|\|\|\|$P$ & \|\|\|\|\|\|$\|^{*}$ \\
\hline 2-6_10V20 & 1111111111 & 1111111111 & 1111111111 & \|\|\|\|\|\|$\|^{*}$ \\
\hline SS1̄0V-24V & $\| 111$ & 1111111111 & 1111111111 & \|\|\|\|\|\|$\|^{*}$ \\
\hline 2-6_10V27 & 11111 & ||||||$G|| \mid$ & 1111111111 & \|\|\|\|\|\|$\|^{*}$ \\
\hline 2-6_10V33 & 1|||||| & 1111111111 & |||||||||| & \|\|\|\|\|\| \\
\hline 2-6_11V04 & & & & \\
\hline 2-6_11V08 & & & & \\
\hline 2-6_11V & & & & \\
\hline 2-6_11V17 & 1111111111 & 1111111111 & \|\|\|\|\|\| $\mid \|$ & \|\|\|\|\|\|$\|^{*}$ \\
\hline
\end{tabular}

Supplementary Figure 6. Amino acid alignment of capsid proteins from 15 CtenDNAV-II strains. The consensus sequence is displayed in grey and the mutations in colour. The amino acids are organised in the same scheme as in Figure 2 with divisions into 70 residues per line, which are further subdivided into blocks of 10 residues by spaces within the sequence. The N-termini were not successfully sequenced and the first residue is therefore P81. This paper describes the structure of strain SS10V-8V. 
786

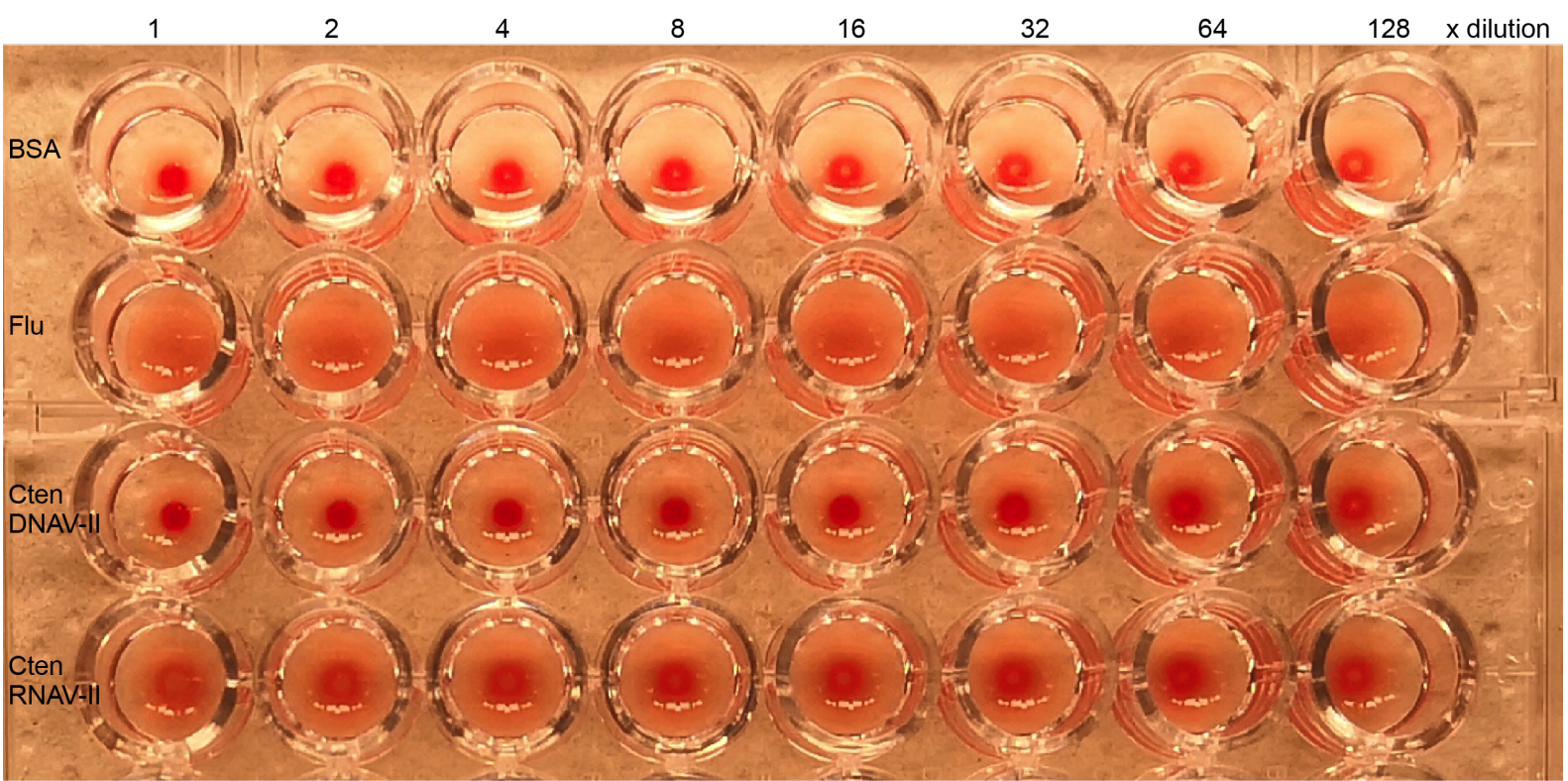

788 Supplementary Figure 7. Hemagglutination inhibition assay. Twofold serially diluted $1 \mathrm{mg} / \mathrm{mL}$ 789 BSA, influenza virus (flu), CtenDNAV-II and CtenRNV-II are tested for HI activity. The BSA and flu 790 were used for negative and positive controls for the assay. 

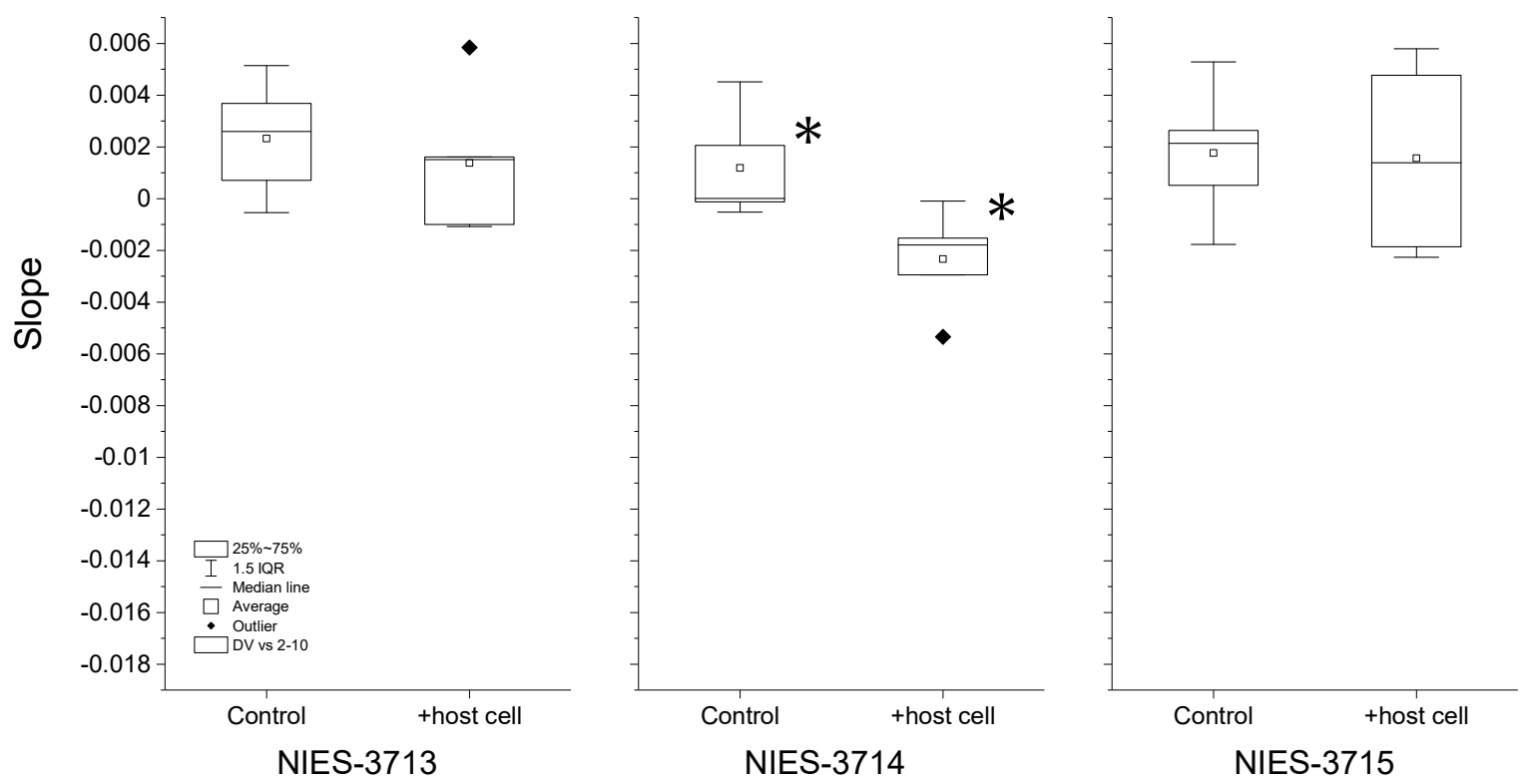

\section{CtenRNAV-II}
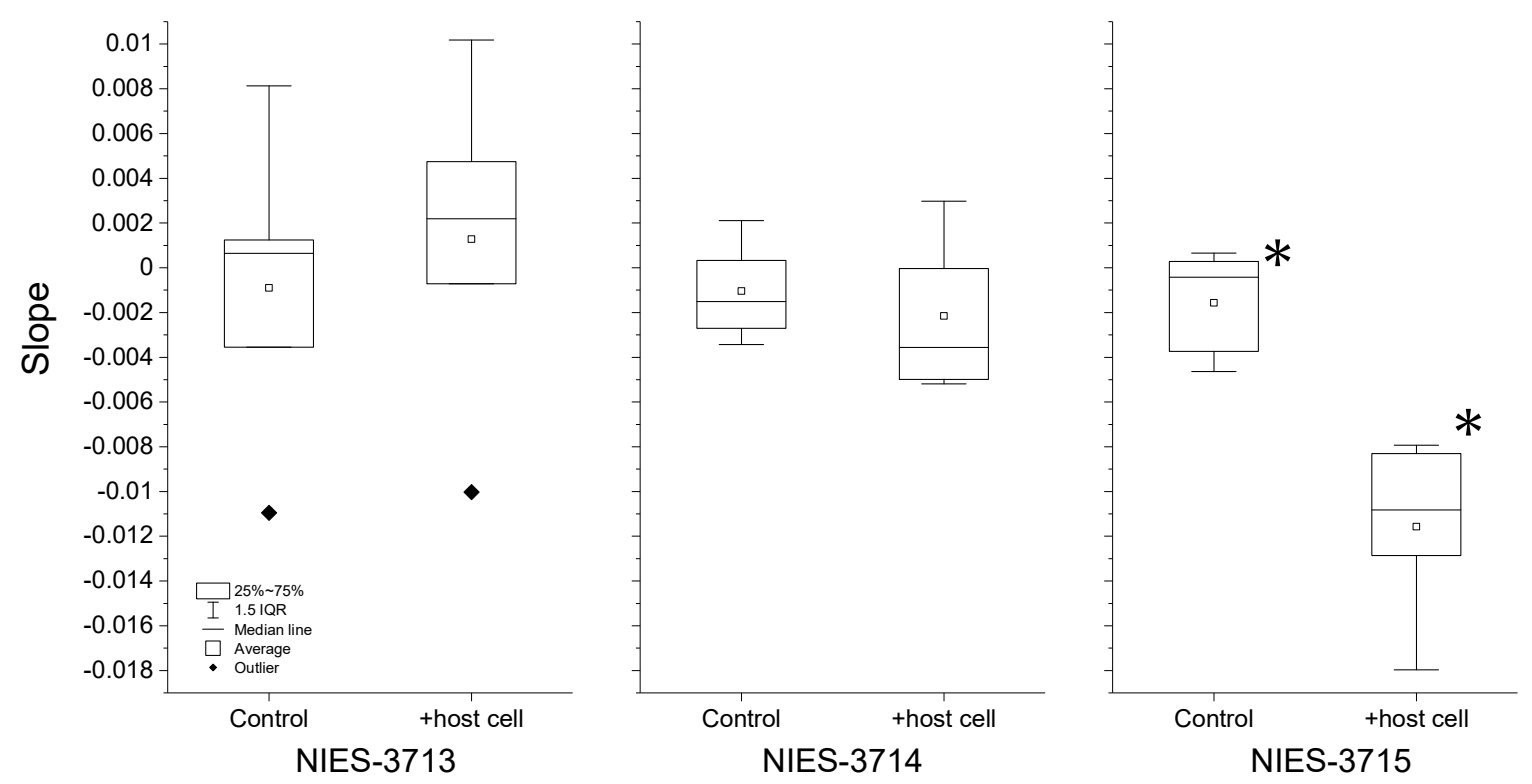

794 Supplementary Fig. 8. Adsorption tests between viruses and diatoms. The results are shown in 795 slope of free virus titer in a culture for $2 \mathrm{~h}$ (see materials and methods). Significant differences were 796 detected in CtenDNAV-II vs. NIES-3714, and CtenRNAV-II vs. NIES-3715 (t-test, $\mathrm{p}<0.05, \mathrm{n}=5$ ). 797 Their adsorption coefficients were $1.4 \pm 0.9 \times 10^{-9} \mathrm{~mL} \mathrm{~min}^{-1}$ and $2.7 \pm 1.1 \times 10^{-9} \mathrm{~mL} \mathrm{~min}^{-1}$, respectively. 798 NIES-3713: Chaetoceros socialis f. radians; NIES-3714: Chaetoceros tenuissimus; NIES-3715: Chaetoceros tenuissimus. 

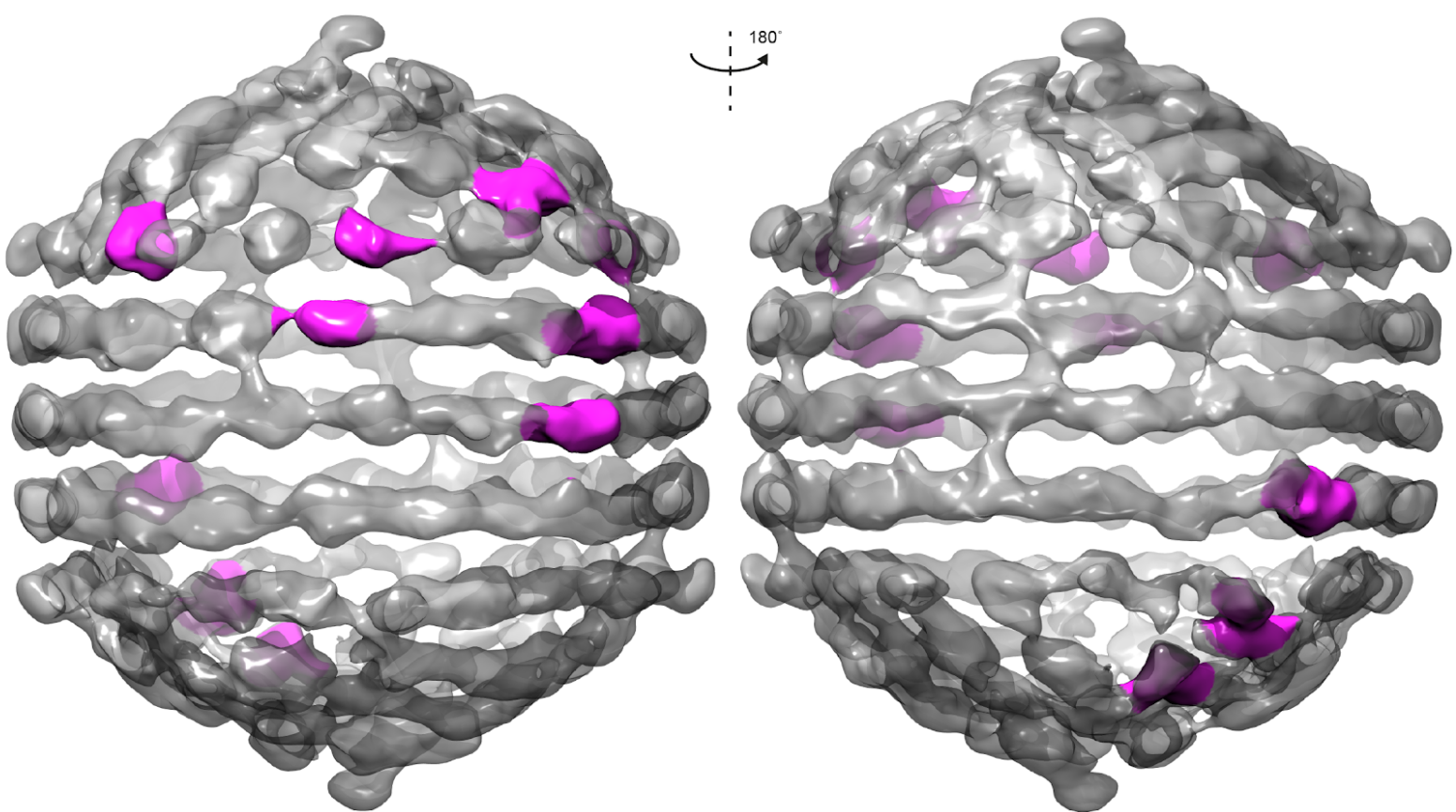

801 Supplementary Figure 9. Connections between the outer genome layer and the core. The outer 802 genome layer where the sites that connect to the core are highlighted in magenta. The connections between the outer genome layer and the core seem to be confined to two specific areas on approximately opposite sides. One area is shown in the left panel and the second is shown to the right, which is rotated $180^{\circ}$. 


\section{Supplementary methods}

808

809

810

811

812

813

814

815

816

817

818

819

820

821

822

823

824

825

826

827

828

829

830

831

832

833

834

835

836

837

838

839

840

\section{Sequencing of viral capsid protein gene}

Two hundred $\mu \mathrm{L}$ of $C$. tenuissimus NIES-3715 strain culture was added to each well of a 96-well culture plate, and $10 \mathrm{uL}$ of virus strains (SS10V-8V, SS10V-24V, SS10V-35V, 2-6_10V-05, 26_10V-07, 2-6_10V-17, 2-6_10V-20, 2-6_10V-27, 2-6_10V-33, 2-6_11V-04, 2-6_11V-06, 2-6_11V$\left.08,2-6 \_11 \mathrm{~V}-10,2-6 \_11 \mathrm{~V}-12,2-6 \_11 \mathrm{~V}-17\right)$ isolated from $C$. tenuissimus were added to each separate well. Diatom cultures with viral solution were grown at $15{ }^{\circ} \mathrm{C}$ in modified SWM3 medium (Kimura and Tomaru, 2015) under a 12/12-h light-dark cycle of ca. 110-150 mmol of photons / $\mathrm{m} 2 / \mathrm{s} 1$ by using white fluorescent illumination. After 24 hours of viral inoculation, the cultures were transferred to microtubes and the cells were pelleted by centrifugation. One hundred $\mathrm{uL}$ of TE were added to each cell pellet, and they were heated at $100{ }^{\circ} \mathrm{C}$ for $10 \mathrm{~min}$. These solutions were used as DNA samples. The PCR reaction was conducted as follows: 1 cycle at $94{ }^{\circ} \mathrm{C}$ for $2 \mathrm{~min}, 25$ cycles each at $94{ }^{\circ} \mathrm{C}$ for 30 $\mathrm{s}, 60^{\circ} \mathrm{C}$ for $30 \mathrm{~s}, 72^{\circ} \mathrm{C}$ for $1 \mathrm{~min}$, and 1 cycle at $72{ }^{\circ} \mathrm{C}$ for $10 \mathrm{~min}$. The primer set of middle part of the gene (P31_CtDV-Ari-F2: 5'-AGCAACCACAAATCCCCG-3'; P32_CtDV-Ari-R1: 5'ATTTTGAATAGCGTTTACAATGAG-3') and the primer set of last part of the gene (CtD2V_VP2inF1: 5'-AATACTAGTGCCATTCGTCC-3', CtD2V_VP2outR2: 5'ACTACCATCATGATTGAGACTG-3'), they detect the gene for the viral capsid protein were used. Each PCR product was purified with the ISOSPIN PCR Product (Nippon gene, Tokyo) and sequenced on an ABI 3130 DNA Analyzer using the Sanger dideoxy method. Each DNA sequence was combined and converted to amino acid sequences. The partial capsid protein amino acid sequences of each virus were automatically aligned using Clustal W.

\section{Hemagglutination inhibition $(\mathrm{HI})$ assay}

The HI test was performed according to classical procedures. The purified BSA, influenza virus (flu), CtenDNAV-II and CtenRNAV-II were adjusted to $1 \mathrm{mg} / \mathrm{mL}$ in PBS. Twofold serial dilutions of these samples were prepared for the assay, of which $25 \mu \mathrm{L}$ of each dilution was incubated with $50 \mu \mathrm{L}$ of 125 times PBS-diluted red blood cells from sheep blood (Håtunalab). The assay was conducted in a Vbottom, 96-well plate. The plate was incubated for $1 \mathrm{hr}$ at RT, and used for observing the hemagglutination of the red blood cells.

\section{Adsorption test}

\section{Host diatom}

The virus adsorption kinetics of CtenDNAV-II and CtenRNAV-II was examined using the following diatom strains: Chaetoceros socialis f. radians NIES3713, C. tenuissimus NIES-3714 and C. tenuissimus NIES-3715. Previously reported compatibilities between host diatoms and viruses based on (Kimura and Tomaru, 2015) are as following:

\begin{tabular}{|l|l|l|}
\hline & CtenDNAV-II & CtenRNAV-II \\
\hline C. socialis f. radians NIES3713 (L-4) & Not lysed & Lysed \\
\hline C. tenuissimus NIES-3714 (2-6) & Lysed* & Not lysed \\
\hline C. tenuissimus NIES-3715 (2-10) & Lysed & Lysed* \\
\hline
\end{tabular}

*original host-virus combination

\section{Viral inocula}

Exponentially growing cultures of $C$. tenuissimus NIES-3715 were inoculated with CtenDNAV-II and CtenRNAV-II $\left(0.1 \% \mathrm{v} \mathrm{v}^{-1}\right)$, which were stored at $4^{\circ} \mathrm{C}$ in the dark, and incubated for $7 \mathrm{~d}$ under the growth conditions described above. Lysates were passed through a $0.2-\mu \mathrm{m}$ polycarbonate membrane 

remove cellular debris and stored at $4{ }^{\circ} \mathrm{C}$. Filtered lysates were used as experimental inocula.

The number of infectious viral units was determined using the extinction dilution method (Suttle, 1993). Briefly, stored filtrates were rapidly thawed at $25^{\circ} \mathrm{C}$, and then diluted with $\mathrm{SWM} 3$ medium in a series of 10 -fold dilution steps. Aliquots $(100 \mu \mathrm{L})$ of each dilution were added to 8 wells in cellculture plates with 96 flat-bottom wells and mixed with $150 \mu \mathrm{L}$ of an exponentially growing host algae culture, $C$. tenuissimus NIES-3715. The cell culture plates were incubated at $20^{\circ} \mathrm{C}$ under a $12: 12$ $\mathrm{h}$ light:dark cycle of $130-150 \mu \mathrm{mol}$ photons $\cdot \mathrm{m}^{-2} \mathrm{~s}^{-1}$ (cool white fluorescent illumination) and cultures were monitored using an optical microscope (Nikon Ti, Tokyo, Japan) for up to $14 \mathrm{~d}$ for culture lysis. Culture lysis due to viral infection was usually observed as a complete degradation of the host cells in a well. Virus abundance was calculated from the number of wells in which algal lysis occurred using a BASIC programme as previously described (Nishihara et al., 1986).

\section{Adsorption test}

860 The host cell cultures were grown in SWM3 medium under a 12:12 h light:dark cycle of 861 approximately $400 \mu \mathrm{mol}$ of photons $\cdot \mathrm{m}^{-2} \mathrm{~s}^{-1}$ using white LED illumination at $25^{\circ} \mathrm{C}$ for C. tenuissimus (NIES-3714 and -3715 ) and $20^{\circ} \mathrm{C}$ for $C$. socialis f. radians (NIES-3713). Cell counts were performed immediately with no fixation using Fuchs-Rosenthal hemocytometer or an image-based cytometer (Tali ${ }^{\circledR}$ Image Cytometer, Thermo Fisher Scientific Ltd., Waltham, MA, USA) (Tomaru and Kimura, 2016). When the cultures reached stationary phase, cell concentration of $>10^{6}$ cells $\mathrm{mL}^{-1}, 20 \mathrm{~mL}$ of the culture was poured into a sterilized polystyrene flask $(n=5)$. An aliquot of the culture was passed through a $0.2 \mu \mathrm{m}$ pore sized filter to remove the diatom cells. The resultant filtrate was poured into the polystyrene flask as a control $(\mathrm{n}=5)$. The virus suspensions were inoculated into these cell-suspended and filtrate cultures at $0.1 \% \mathrm{v} / \mathrm{v}(20 \mu \mathrm{L})$. The virus inoculations were conducted during $1 \mathrm{~h}$ and $2 \mathrm{~h}$ after the light cycle started. The final virus titers in the cultures were set at $10^{5} \sim 10^{6}$ infectious units $\mathrm{mL}^{-1}$ (multiplicity of infections $=10^{-1} \sim 10^{0}$ ).

Aliquots of the cultures were sampled at just after virus inoculations $(0 \mathrm{~h}), 1 \mathrm{~h}$ and $2 \mathrm{~h}$ of post inoculation. The samples were used for cell counts and unadsorbed virus enumeration. The samples used for viral titer estimations (infectious units $\mathrm{mL}^{-1}$ ) were passed through $0.2-\mu \mathrm{m}$ filters (DISMIC ${ }^{\circledR}$ 25CS020AS, Advantec, Tokyo, Japan) to remove cellular debris. Filtrates were stored at $-80^{\circ} \mathrm{C}$ until analysis.

The adsorption coefficient $\left(\mathrm{Cd} ; \mathrm{mL} \mathrm{min}^{-1}\right)$ was determined as follows (Tarutani et al., 2006):

$$
C_{d}=\frac{\alpha-\alpha_{C}}{N}
$$

where $\alpha\left(\min ^{-1}\right)$ and $\alpha_{c}\left(\min ^{-1}\right)$ is the slope determined by linear regression for the natural logarithm of 